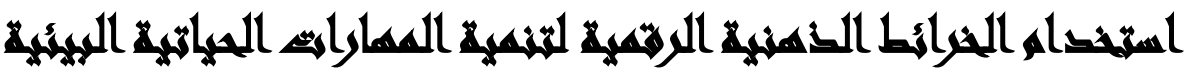

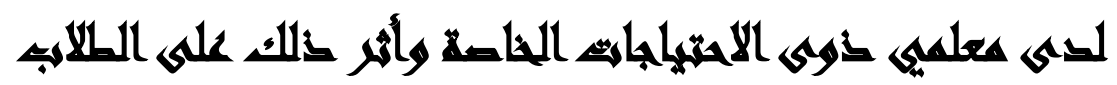

\section{المعاهين سمعياً}

\section{$[1 \mathrm{~T}]$}

\author{
رهام حسن محمد طلبه \\ كلية النكنولوجيه بوسط الوادى، وزارة التعليم العالى والبحث العلىى
}

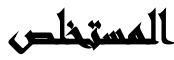

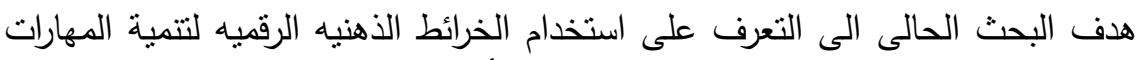
البيئية الحياتيه لدى معلمي ذوى الاحتياجات الخاصة وأثنر ذلك على الطيل الطلاب المعاقين سمعيا

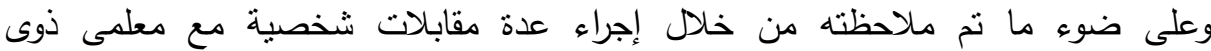

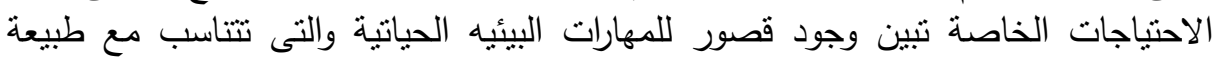

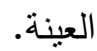

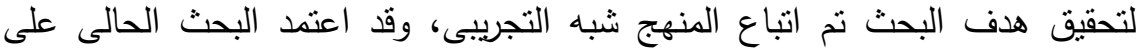

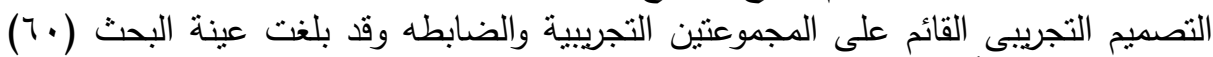

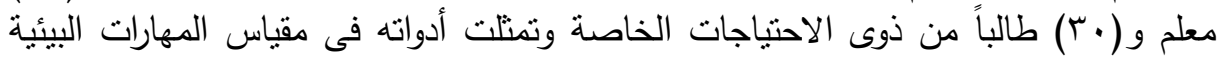

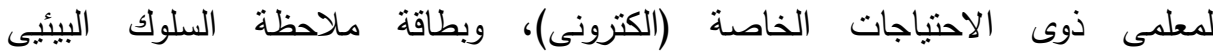

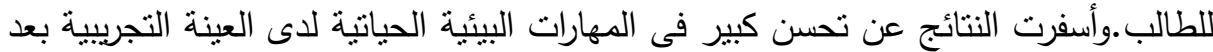

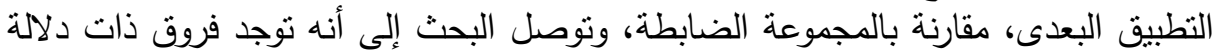

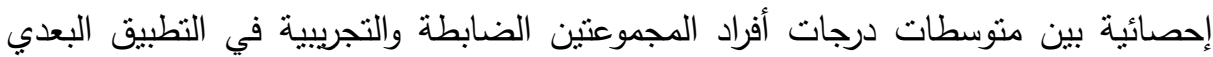

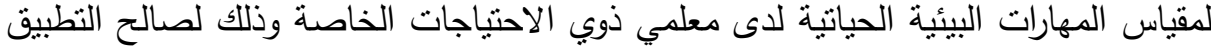

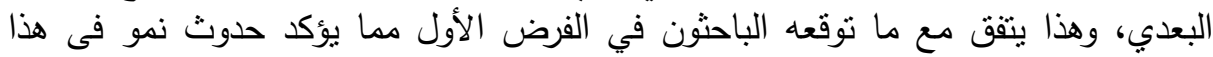

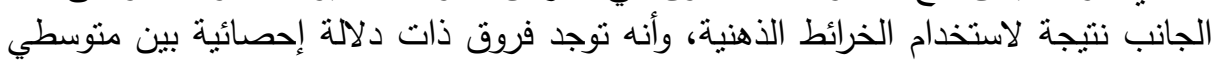
درجات الطلاب في النطبيقين القبلي والبعدي لبطاقة ملاحظة السلوك الإيجابي نحو البانية البيائة وذللك لصالح التطبيق البعدي، كما توجد علاقة ارتباطية موجبة دالة إحصائياً بين نتمية التباية

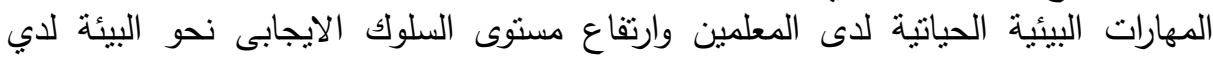




\section{المهابs}

تحظي المشكلات البيئية اليوم بالاهتمام العالمي الذي تجلي في إنشاء الأمم المتحدة

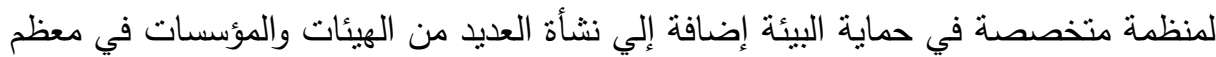
الدول والتي تنبي فلسفتها علي قضايا البيئة وحمايتها من المشكلات والأضرار المؤثرة عليها. وقد أوضحت العديد من الدراسات أهمية تضمين المهارات الحياتيه البيئية بمناهج الدراسة وربطها بالقضايا والمشكلات البيئية، حيث إن الهدف العام للتربية البيئية هو إعداد

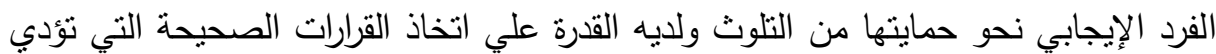
إلي الحفاظ علي التوازن البيئي، وتحمل المسئولية والمهارات العلمية التي تمكنه من العمل

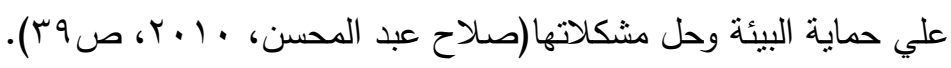
هناك عديد من الدراسات التى اهتمت بدراسة المتطلبات التربوية للطلاب المعاقين

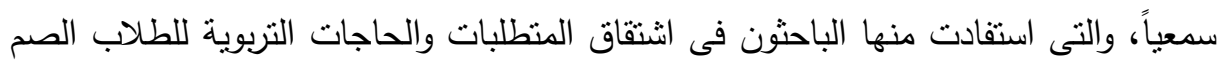

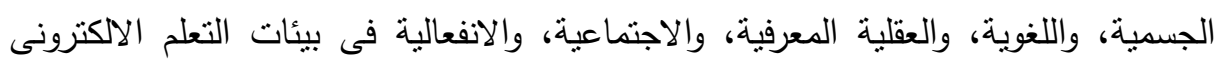
ويمكن توضيح ذلك فيما يلى - تقبل المعاق سمعياً للمتغيرات نتيجة النمو الجسمى. - استغلال جميع الحواس غير السمعية فى العملية التعليمية، والاهتمام بالوسائل التعليمية والتتويع فيها بقدر المكان لنتاسب الفروق الفردية بين المعاقين سمعياً.

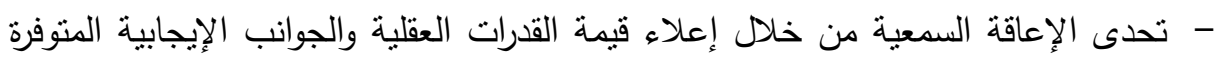

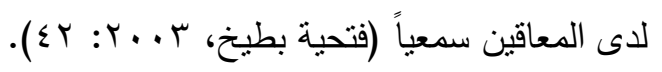

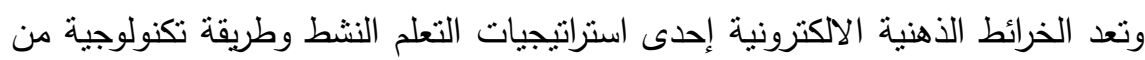
طرق التفكير والتعلم المرئي لجعل المتعلمين مشاركين ومندمجين فى عملية تعلمهم لكونها أداة تستخدم العصف الذهني لتوليد الأفكار وتتابعها بشكل أكثر يساعد على التذكر واستدعاء

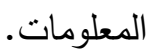




\section{And}

لا يزال العالم يعاني من استمرار حدوث جرائم نلويث البيئة واستنزاف مواردها وما يتبع

ذللك من أضرار جسيمة علي التوازن البيئي ونقاء وصلاحية عناصر البيئة المختلفة وحيث أن الإنسان هو أحد عناصر البيئة الفعالة، فلابد من تتمية المهارات الحياتية البيئية لديه لما لها ولاهي من تأثثر علي سلوكه البيئي.

من هذا المنطلق لجأت الدولة إلي تضمين البعد البيئي في المناهج الدراسية وذللك لتتمية

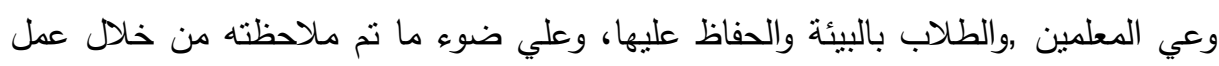

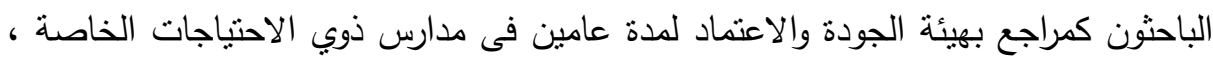
وإجراء الباحثون بعض المقابلات الثخصية المفتوحة فى بعض المدارس دوى الاحتياجات

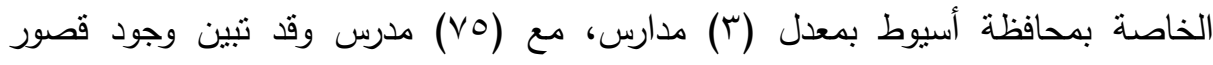

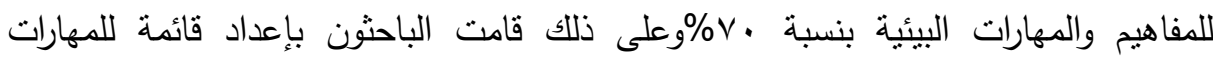
الحياتية البيئية ،والاطلاع على بعض اصدارت جهاز شئون البيئة والمواقع البيئية بشبكة الانترنت في مجال القضايا والمشكلات البيئية.

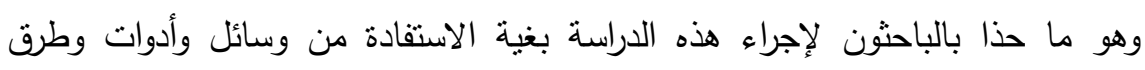

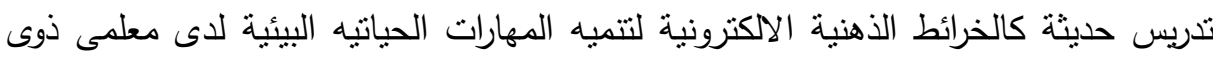
الاحتباجات الخاصة وينعكس أثر ذلك على الطلاب المعاقين سمعياً.

\section{أسئلا الصورامة}

بناء على ماسبق تتبلور مشكلة الدراسة فى التساؤل التالى: "ما فاعلية استخدام الخرائط الذهنية الرقمية لتنمية المهارات الحياتية البيئية لاى معلىي ذئورى الاحتياجات الخاصة وأثر

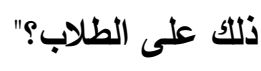


ويتقرع عن هذا السؤال الأسئلة الفرعية التالية:

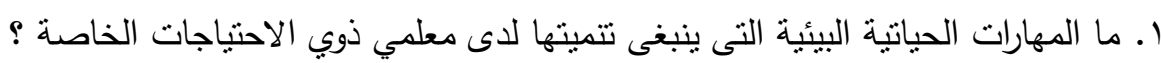

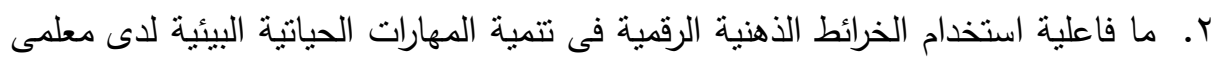

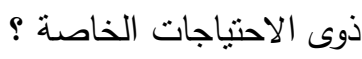

r. ما فاعلية استخدام الخرائط الذهنية الرقمية فى تتمية المهارات الحياتية البيئية لدى معلمى ذوى الاحتياجات الخاصة ؟ واثر ذلك على الطلاب؟ الخه

\section{أهمه المهيد}

تكمن أهميه البحث فى النقاط التالية: 1-توجيه أنظار المهتمين بتقديم المحتوى الإككترونى وأنشطته نحو الاستعانة بتطبيقات

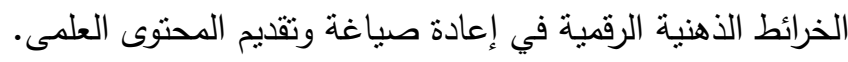

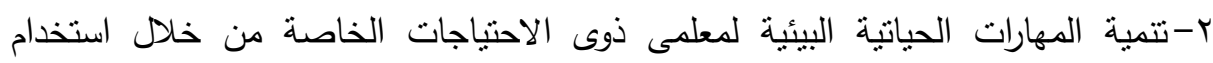
الخرائط الذهنية الرقمية. r-يفعل هذا البحث المدخل التكاملى الذى يحث على تكامل التعليم الإكترونى مع التعليم التقليدى. ع-قد يسهم هذا البحث في فتح مجال امام دراسات اخرى ذات علاقة بهدف استخدام الخرائط الذهنية الرقمية واستخدامها كمعيار لاختيار المعلمين لمهنة التدريس. ه-قد تقيد نتائج البحث الحالى في تبني أساليب جديدة لتتمية المهارات الحياتية البيئية لدي لدئي المعلم بصفة خاصة، والطالب بصفة عامة.

\section{أهساهـ المهيث}

يهدف هذا البحث إلى تحقيق الأهداف التالية:

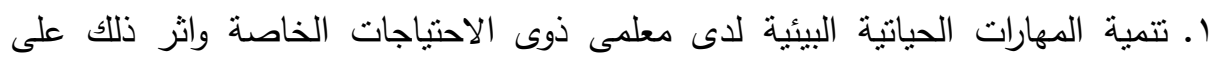

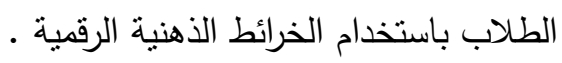

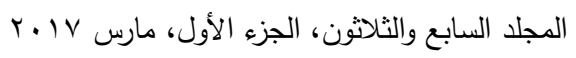


r. تحديد نطبيقات الخرائط الذهنية الرقمية التى يمكن توظيفها عبر أنظمة التعليم الإكترونى.

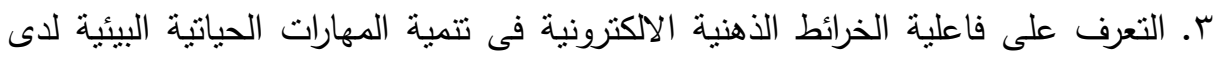

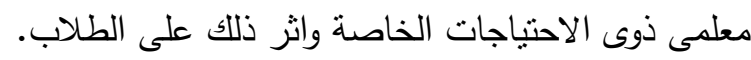

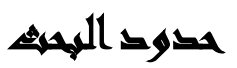

الحدود الموضوعية: يقتصر الموضوع على وضع تصور الخرائط الذهنية الرقمية لتتمية المهارات الحياتية البيئية لمعلىى ذوى الاحتباجات الخاصة ، وقياس أثره على سلوكيات الطلاب نحو البيئة . الحدود البشرية: يقتصر التطبيق على: معلمى ذوى الاحتياجات الخاصة بإدارة أسيوط التعليمية. طلاب ذوى الاحتباجات الخاصة سمعياً (الصم) الخاصة بإدارة أسيوط التعليمية؟ بادئ الحدود الزمنية: تم تطبيق التصور المقترح خلال العام الدراسي 1 أـ م. م.

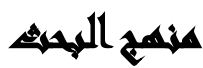

يعتمد البحث الحالى على المنهج شبه التجريبى الذى يهتم بدراسة تأثير متغير مستقل

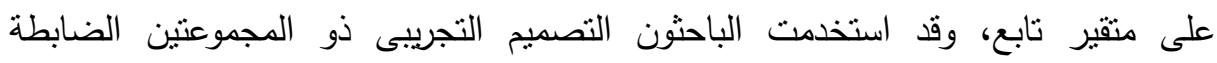

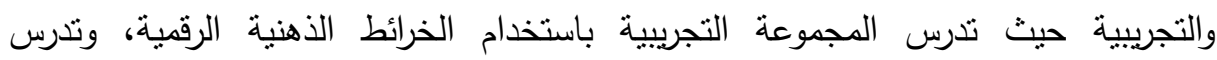
المجموعة الضابطة باستخدام الطريقة التقليدية. وقد نم استخدام المنهج شبه التجريبي في البحث الحالي للكثف عن العلاقة بين المتغيرات التالية: I. المتغير المستقل Independent variable: الخرائط الذهنية الرقمية. r rependent المتغير التابع التمية المهارات الحياتية البيئية. استخدمت الباحثون القياس القبلي والبعدي، على عينتى البحث والتى تضم: لتهيه • عدد (7) معلم ذوى الاحتباجات الخاصة بإدارة أسيوط التعليمية . • عدد (30) طالباً ذوى الاحتياجات الخاص سمعياً( الصم) الخاصة بإدارة أسيوط التعليمية.

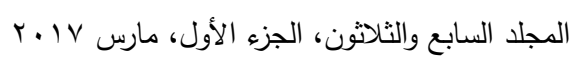




\section{هغوضر القراسما}

سعى البحث الحالي إلى التحقيق من مدى صحة الفروض التالية: ا. توجد فروق ذات دلالة إحصائية بين منوسطات درجات أفراد المجموعتين الضابطة والتجريبية في النطبيق البعدي لمقياس المهارات الحياتية البيئية لدى معلمي ذوي الاحتياجات الخاصة وذلك لصالح التطبيق البعدي r.توجد فروق ذات دلالة إحصائية بين منوسطي درجات الطلاب في التطبيقين القبلي والبعدي لبطاقة ملاحظة السلوك الإيجابي نحو البيئة وذللك لصالح التطبيق البعدي.

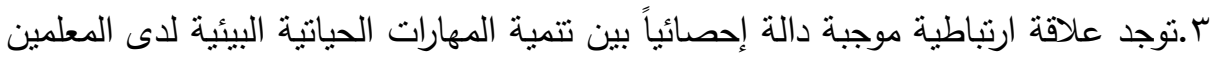
وارتفاع مستوى السلوك الايجابى نحو البيئة لدي الطلاب.

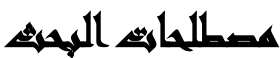

الخرائط الذهنية الرقمية: تعرف الخريطة الذهنية الإكترونية بأنها: إستراتيجية تعليمية لربط

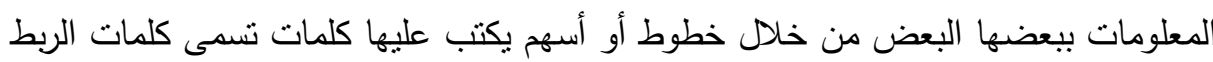

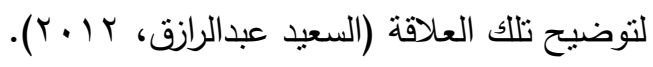

وتعريف اجرائياً فى البحث الحالى بأنها:" هى إحدى استراتيجيات التعلم النشط التى

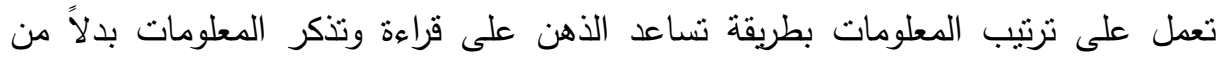

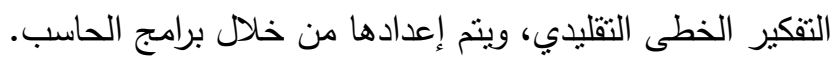
المفهوم البيئي: "إدراك العلاقات الموجودة بين الظواهر أو الاحداث أو الاشياء ذات الصلة بالبيئة وعناصرها ثتتظيم تلك الظواهر والاحداث أو الاثباء في أصناف أقل عدداً منها، فالمفهوم البيئي ما هو الا صيغة محددة للخطوط المشتركة بين مجموعة من الحقائق

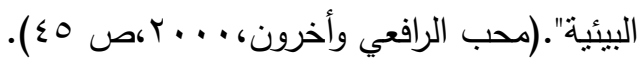


المهارات الحياتية البيئية: "هي عملية يستخدما كل الأفراد ، وعلي جميع مستويات النضج لاكتشاف أو انتاج علاقات جديدة بين الأشياء الملحوظة أو المحسوسة، وتلك العملية

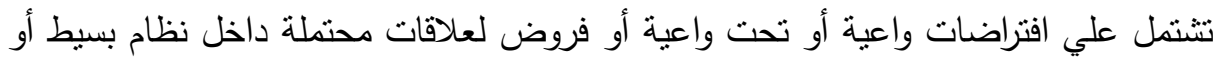

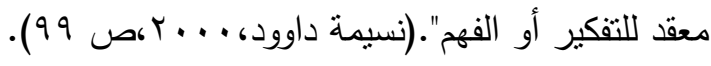
وتعرف اجرائيا فى هذا البحث" هى دجموعة من المهارات التى يتعلمها معلمو ذوى الاحتياجات الخاصة بصورة منظمة عن طريق الأنشطة والتطبيقات العلمية المرتبطة بالبيئة التى يعيش فيها،والتى تمكن من التعامل مع مقتضيات الحياة اليومية بنجاح وتهذف الى بناء

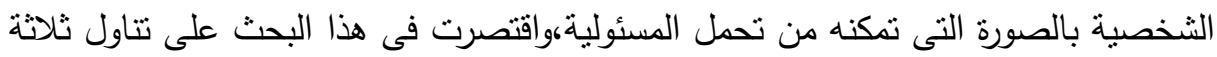
مهارات رئيسة ،المهارات الغذائية، المهارات الصحية، المهارات الوقائية".

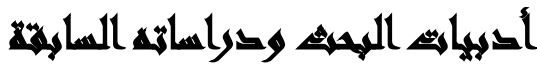

أولاً: أدبيات البحث: المحور الأول: الخرائط الذهنية الإكترونية: تعد الخرائط الذهنية أداة تفكير تتظيمية تساعد على إدخال المعلومات للدماغ ومن ثم استرجاع هذه المعلومات المخزنة، كما إنها طريقة فعالة وإبداعية لأخذ الملاحظات والاستتناجات، وللخرائط الذهنية تركيب طبيعى واحد، حيث أنئ أنها

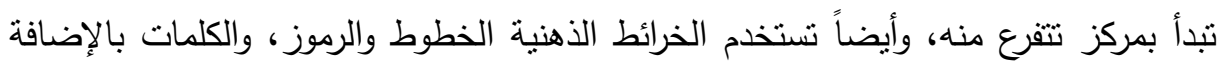
إلى الرسومات التحيلية، وبهذا يمكن تحويل الملاحظات والتلخيصات المملة إلى مخطط منظم Anthony, et al, ) وملون وقابل لتذكر يعمل بشكل متلائم ومماتل لكيفية عمل الدماغ لئهن

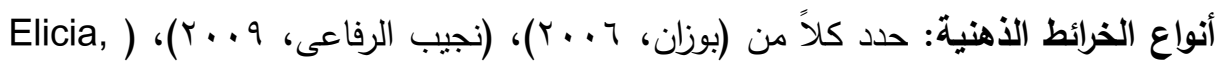
2010) عدة أنواع للخرائط الذهنية من هذه الأنواع: ( ) الخرائط الذهنية الثنائبة: وهى الخرائط التى تحوى فرعين مشعين من المركز .

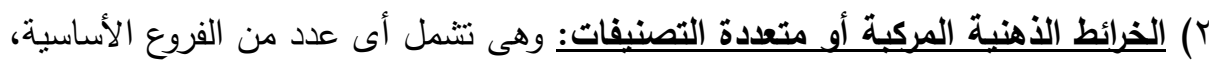

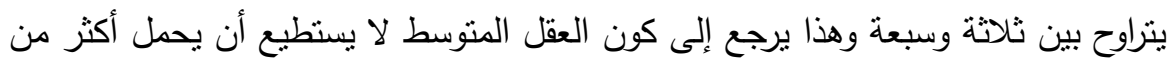

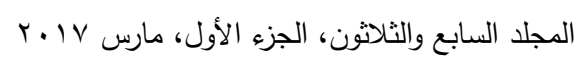


سبع مفردات أساسية من المعلومات، أو سبعة بنود فى الذاكرة قصيرة المدى ومن أهم

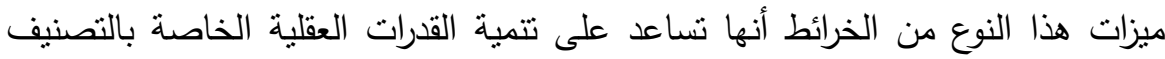
وإعداد الفئات والوضوح والدقة.

r) الخرائط الأهنية الجماعية: وهى يقوم بتصميمات عدد من الأفراد معا فى شكل

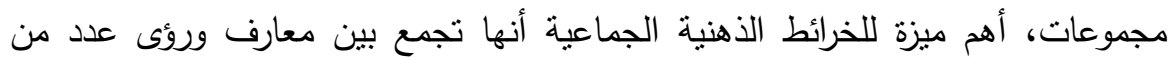

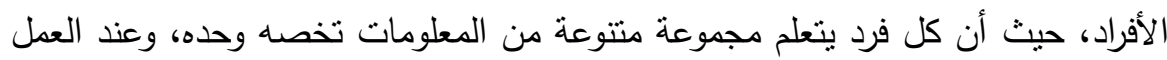
فى مجموعات سوف تتجمع معارف أفراد كل المجموعة، ويحدث ارتجال جماعى للأفكار وتكون نتيجته خريطة ذهنية جماعية رائعة ومميزة.

؛) الخرائط الذهنة المعدة عن طريق الحاسوب: وحديثا يمكن أن تقوم بتصميم الخرائط

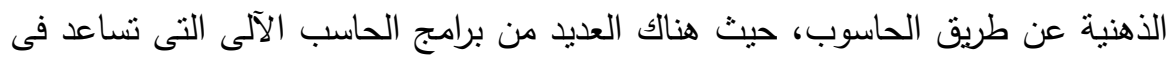
إعداد وحفظ الخرائط، فهناك برامج تساعد على رسم الخريطة الذهنية، وبرامج أخرى تعتبر تطبيق منكامل على الموضوع بصورة مباشرة.

تأثير استعمال خرائط التفكير الخرائط الذهنية: • • تحسن فى تذكر المحتوى أثناء القراءة .

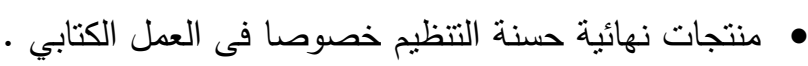
• • فهم أعمق للمفاهيم.

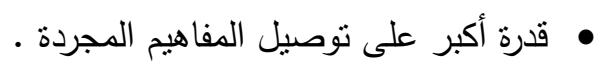

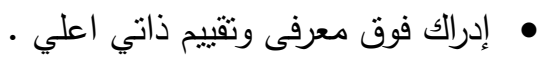
• • (تقم فى الإبداع وفى الروية.

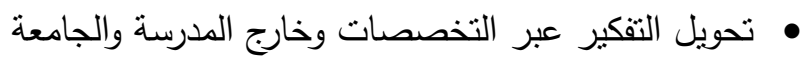

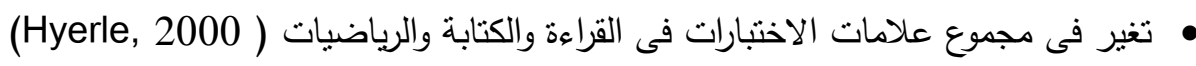
الإستراتيجية التعليمية للخرائط الذهنية:

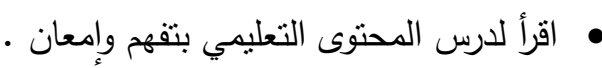
• حد الأفكار الرئيسية التي يشتمل عليها المحتوى التعليمي والأفكار الثانوية ( الفرعية).

$$
\text { المجلد السابع والثلاثون، الجزء الأول، مارس VI P. }
$$


• حدد العلاقات التى ترتبط بين هذه الأفكار بعضها ببعض •

• ارسم شكلا ( خريطة )تصور هذه الأفكار الرئيسية والثانوية ثم خطوطا نصل برنه بينها

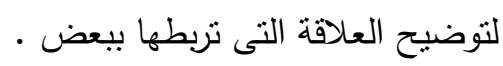

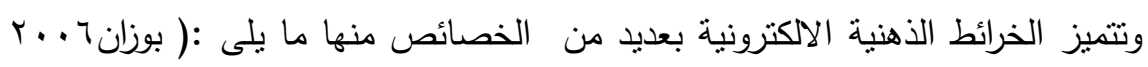
.(serrate, 2009

$$
\text { • تبلور الموضوع الرئيسي( محور الاهتمام فى صورة مركزية . }
$$

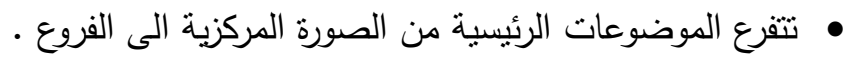

• الفروع تشكيل هيكلي متصل بالموضوع الرئيسي.

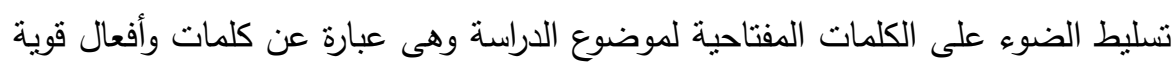
تناعد على التركيز ويتم طرح الأفكار من خلالها.

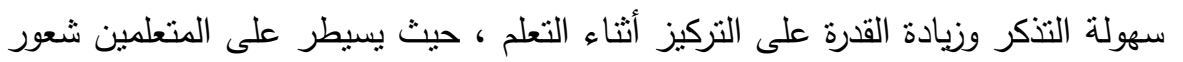
بالتقة فى النفس وفى القدرات العقلية . فكر مثل الحاسب الالى ، اى على شكل خطوط مستقيمة طويلة ومتتالية يفكر بطريقة

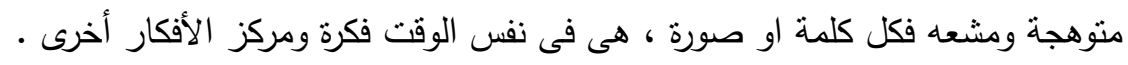

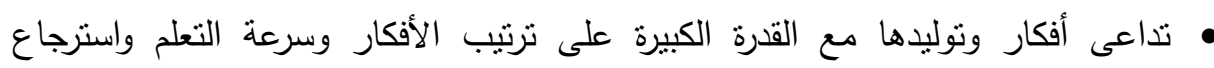

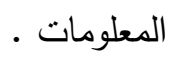

والخارطة الذهنية هي وسيلة تعبيرية عن الأفكار والمخططات بدلا من الاقتصار على

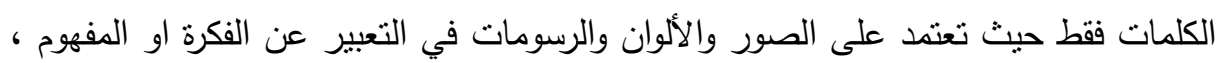

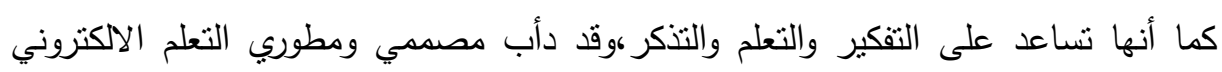
لإيجاد طرق مبتكرة لاستخدام الخرائط الذهنية فى مجال التعليم والتعليم الالكتروني .

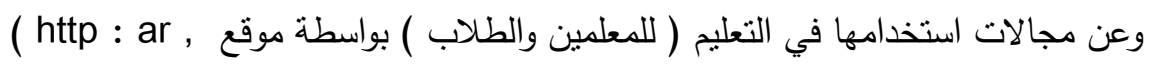
. Wikipedia, org / wiki/

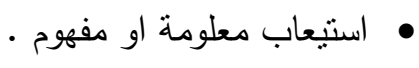
• مراجعه وحدة دراسية . 


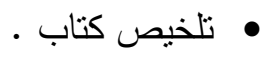

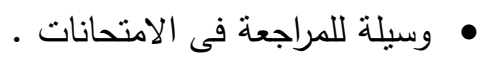

$$
\begin{aligned}
& \text { • • ترتيب خطوات مشروع دراسي. }
\end{aligned}
$$

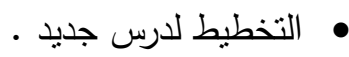

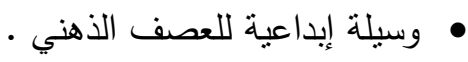

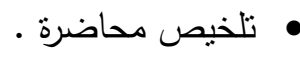

$$
\begin{aligned}
& \text { • • ترتيب الأفكار ( قبل كتابة بحث او تصميم عرض ). }
\end{aligned}
$$

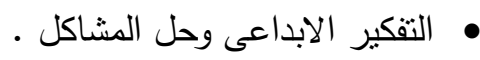

$$
\begin{aligned}
& \text { • اتخاذ القرارات. }
\end{aligned}
$$

وفى إحصائية فى الولايات المتحدة الأمريكية اتضح أن الطالب الذي يعتمد على كتابة عن طريق الخرائط الذهنية أفضل بكثير فى التحصيل من الطابق الذي يكتب كلمة يقولها الأستاذ اثثاء المحاضرة. المكونات الأساسية للخرائط الذهنية الإكترونية: للخريطة الذهنية الالكترونية 7 مكونات رئيسية وهى: الخطوط: لربط الالفكار بعضها ببعض. الأسه:: لتوصيل الأفكار المتتاثرة بالأجزاء ذات العلاقة وتوضيطيح اتجاه سبر الأفكار

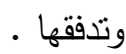
الأثكال الهندسية مثل المربع والدوائر والمستطيل والمعين ....الخ . الصور : باعتبار ان الصورة الواحدة بألف كلمه.

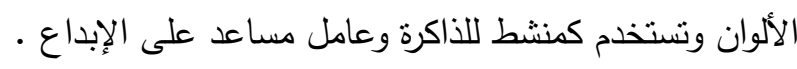
الرموز: ولها نفس قوة الصور فى تقريب الصورة الذهنية عن الأشياء أو الظاهرات وتكوينها 
أمثلة للخرائط الذهنية الاكترونية ومواقع ويرامج إنتاجها: لانتاج الخرائط الاكترونية العديد من المواقع والبرامج أهمه:

Edraw Mind mape9 - Mindomo -Mindmaster -Free mind تم نم اختيار موقع mindomo لشرحة واستخدامة فى انتاج الخرائط الذهنية الكترونية ويتم انتاج الخرائط الذهنية الالكترونية بكثر من طريقة من اهمها انتاجها عن طريق مواقع انشاء

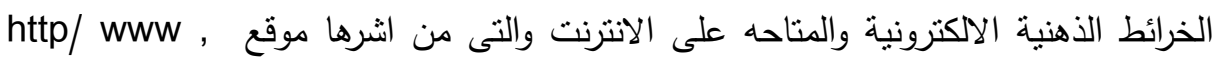

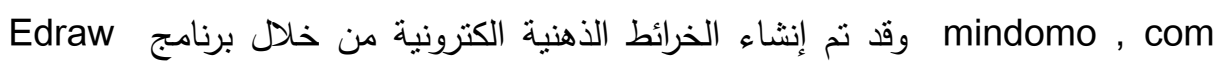
Mind mape9 - يدعم أكثر من خدمة للبرمجيات الاجتماعية منل الثبكات الاجنماعية Face book وقارئ ملخصات الأخبار Rss والمدونات Bolger ويتميز بالتفاعلية والتشاركية والتعلم والعمل التعاونى. - يتيح إمكانية إرسال التقارير عن المتعلمين للمعلم مما يجعل المعلم قادر على متابعة المتعلمين بصورة مستمرة وضروري.

- يتيح للمتعمين أمكانية تنفيذ الأنشطة والمهمات من خلالهه ويتيح درجة عالية من الحماية

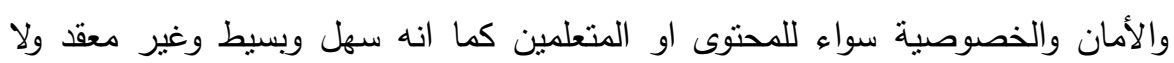

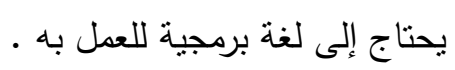

- مناسب لمستوى المتعلمين وخلفياتهم العلمية .

المحور الثانى: الطلاب المعاقين سمعياً وطرق التواصل والفهم معهم: تعد عملية الاتصال جوهر استمرار الحياة الاجتماعية وتطورها، فالحضارة الإنسانية حافظت على بقائها وتطورها

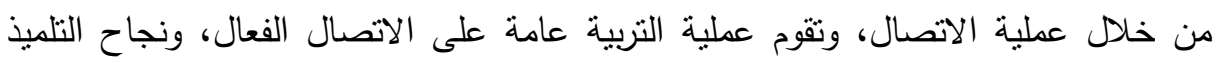
الأصم فى تحقيق الاتصال الفعال مع المجتمع من حوله من الأهداف الرئيسية من رواء تربيته، وذلك لأن الصمم يفرض على ضحائ الصاياه جداراً من العزلة فى حالة استسلام الأصم

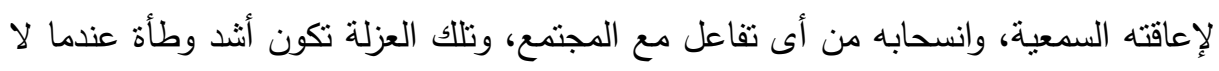

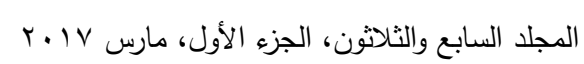


يلتحق الأصم بالمدرسة ولا يحصل على أى قدر من التعليم المنظم؛ ولذلك ليس من المبالغة

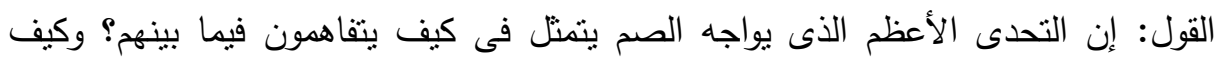

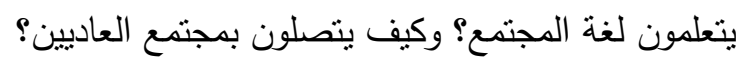

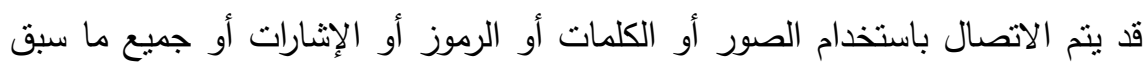

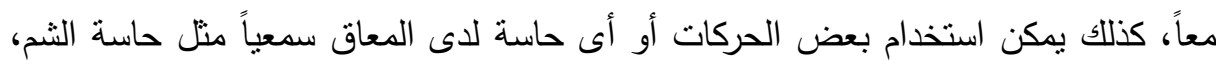

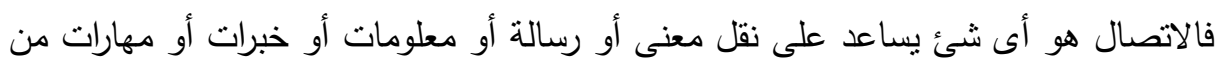

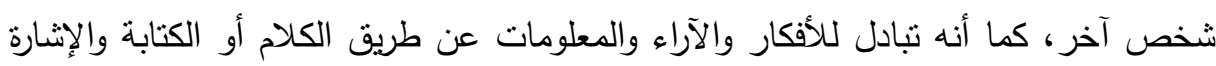

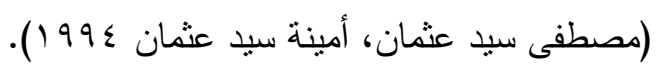

تبين من الكتابات والداسات الخاصة بالمعاقين سمعياً والتى منها: "دونالد" ( Donald,

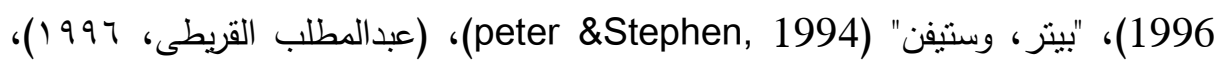

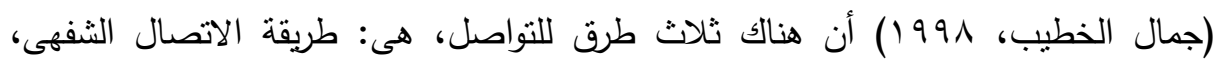
طريقة الاتصال الكلى، طريقة الاتصال اليدوى. 1- طريقة الاتصال الثفهي: تفسر طريقة الاتصال الملفوظ أو الثفهى بأنها قائمة على قراءة الأهبا.

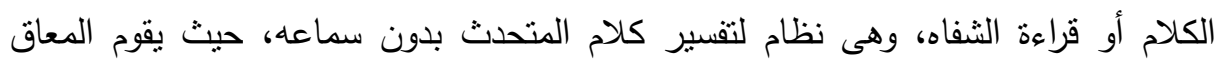

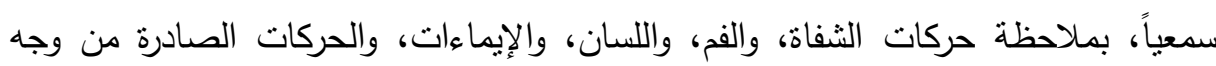

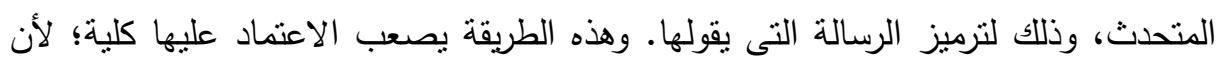

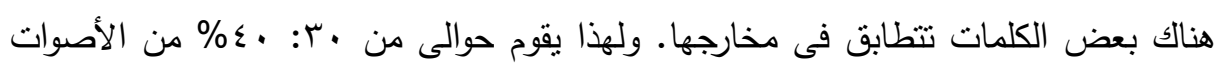

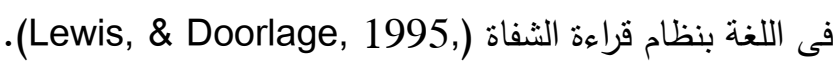

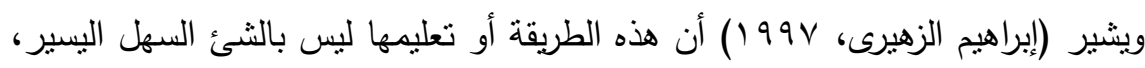

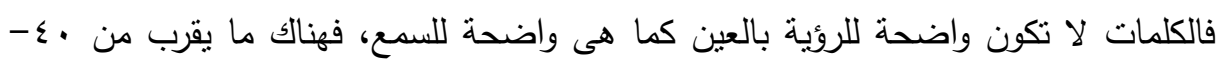

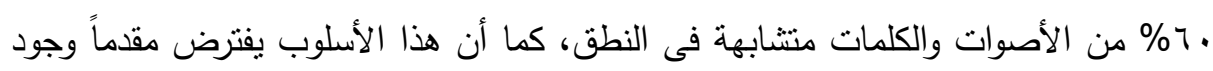
أساس لغوى مناسب، وثزوة لفظية واسعة. لذا فالعديد من الصم لا يتقبلونه. 
ب - طريقة الاتصال الكلى: يرى (جمال الخطيب: 991 (1). أن طريق الاتصال الكلى تستخدم لتحقيق أهداف أساسية هى: نسهيل عملية التواصل اللفظى، نوفير بديل عملى للكلام، إستتارة الدافعية وزيادة مستوى الانتباه، خفض المظاهر السلوكية غير المقبولة.

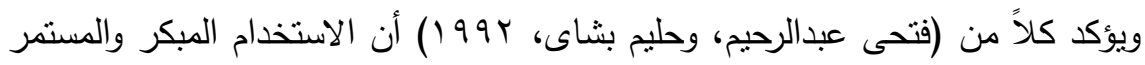

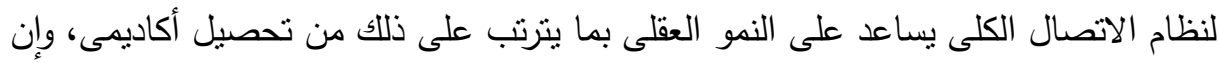

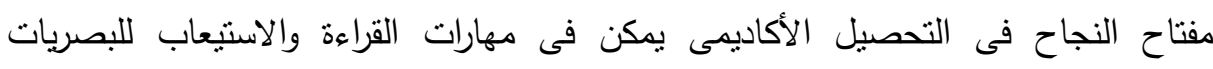
المختلفة، حيث يبنى استيعاب المادة المقروءة وينمو على أساس من الخبرات اللغوية الواسعة،

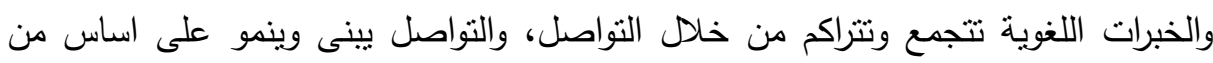
التفاعل الإنسانى، لذلك فإن التفاعل الإنسانى المفيد والمثمر يجب ألا يؤجل بطريقة عشوائية، كذلك يجب عدم خرق التتابع الطبيعى فى العملية النمائية للتواصل على أسس عشوائية.

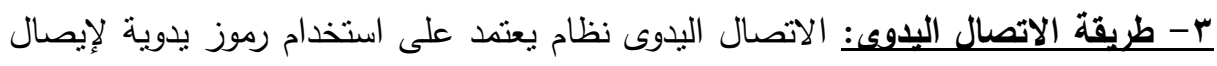

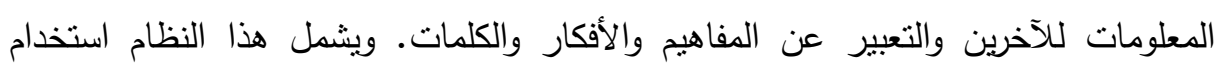
التهجئة بالأصابع، ولغة الإثارة. أ) التهجئة بالأصابع: تنشمل التهجئة بالأصابع استخدام أصابع يد واحدة أو اليدين معاً لتمثيل

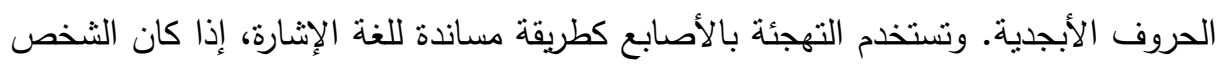

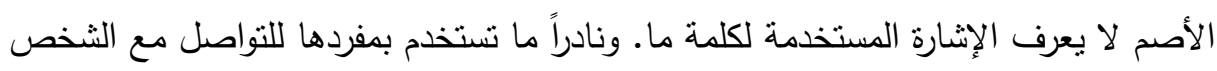

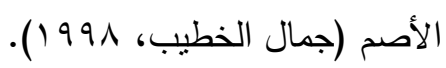

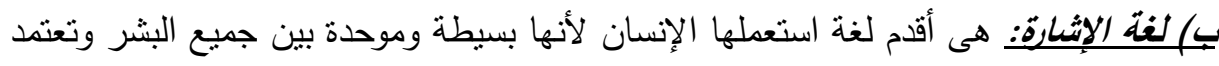

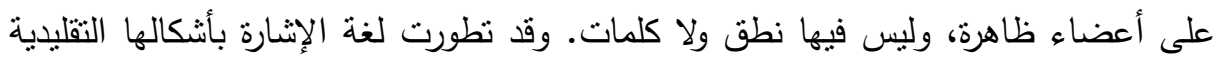
بواسطة المعلمين العاديين والصم، وقد فتح استخدام الاتصال اليدوى فى المدارس أفاقاً جديدة ولطاء

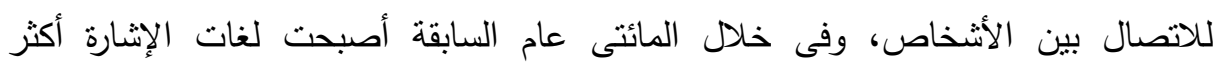
اصطلاحية وتحكمها قواعد، أكثر قبولاً من الناس عامة كأدوات مهمة للاتصال عام والتعليم .(Marc, 1993) 


\section{ثانياً: الدراسات السابقة:}

وفى سياق ذلك نجد أن الخريطة الذهنية الالكترونية من الوسائل الحديثة التي تساعد على تسريع التعلم واكتشاف المعرفة بصورة أسرع من خلال رسم مخطط يوضح المفهوم الاساسى والأفكار الرئيسية والفرعية ويقوم بهذا النشاط المتعلم ذاتيا كما تتميز بقدرتها السريعة فى ترتيب الافكار سرعة التعلم ، استرجاع المعلومات وهو ما جاء فى دراسة جمال

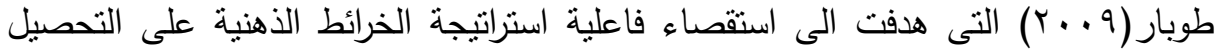
7. الدراسي فى مادة الأحياء لاى طالبات الصف الأول الثانوى وتكونت عينة الدراسة من طالبة تم تقسيمهن الى مجموعتين تجريبية و ضابطه ، وقد تم تدريس وحدة الاخراج فى مقرر الإحياء للمجموعة التجريبية باستخدام الخرائط الذهنية الالكترونية وتم التدريس للمجموعة الضابطه بالطريقة النقليدية، وتوصلت نتائج الدراسة الى تفوق طالبات المجموعة التجريبية على طالبات المجموعة الضابطية، وكان هناك فرق دال إحصائيا بين منوسطي درجات المجموعنين التجريبية والضابطة لصالح المجموعة التجريبية وقد اوصت الدراسة باستخدام إستراتيجية الخرائط الذهنية الالكترونية فى تدريس المواد الدراسية المختلفة والاستذكار .

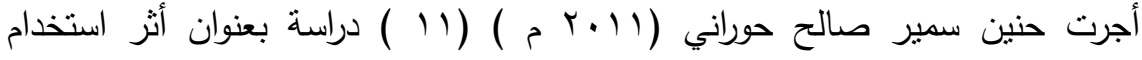
إستراتيجية الخرائط الذهنية فى تحصيل طلبة الصف التاسع فى مادة العلوم وفى اتجاهاتهم

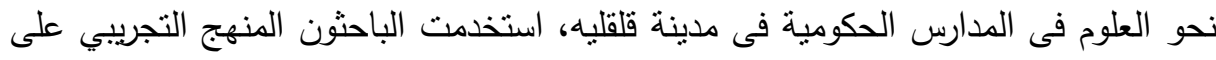

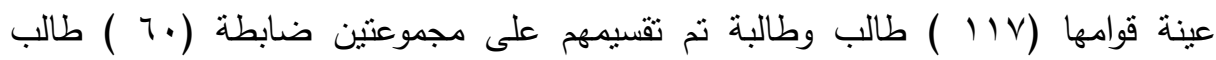
وطالبة، واخرى تجريبية عددها (OV) طالب وطالبة، واستخدمت الباحثون دليل المعلم لاستخدام الخرائط الذهنية واختبار تحصيلي فى العلوم ومقياس الاتجاه نحو العلوم كأدوات

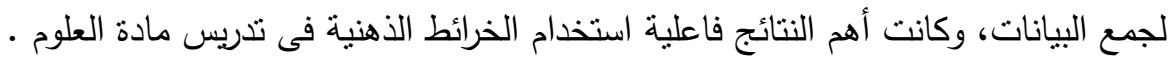

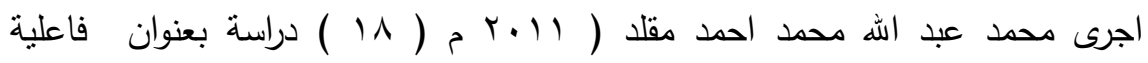
استخدام الخرائط الذهنية المعززة بالوسائط المتعددة فى تدريس الدراسات الاجتماعية على لهـ التحصيل المعرفي وتتمية التفكير الاستدلالي لاى تلاميذ المرحلة الإعدادية استخدم الباحث المنهج التجريبي، على عينه قوامها ( r م ) طالب وطالبة، واستخدمك الباحث اختبار

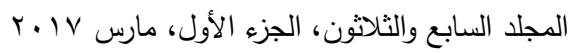


تحصيلي للاراسات الاجتماعية ومقياس التفكير الاستدلالي كأدوات لجمع البيانات وأسفرت أهم النتائج عن فاعلية الخرائط الذهنية وتطبيقاتها بالوسائط المتعددة فى التحصيل المعرفي وتئيلية التئية التفكير الاستدلالي لتلاميذ فى المقرر قيد البحث .

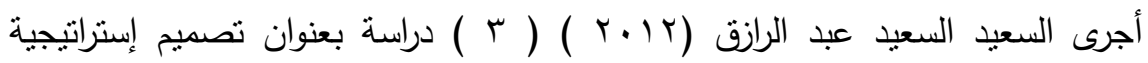
لاستخدام الخرائط الذهنية وأثرها على تتمية التحصيل الدراسي وبعض مهارات الترات التفكير الابداعى فى مقرر تحليل النظم لاى الطلاب المعلمين للحاسب الالى استخدم الباحث

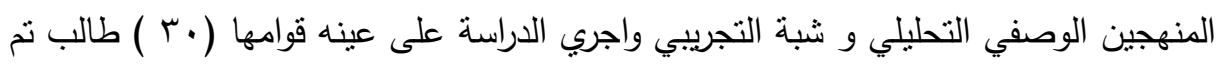
تقسيمه عشوائيا على مجموعتين ضابطة وتجريبية قوام كل منهما (10 ) طالب، واستخدم

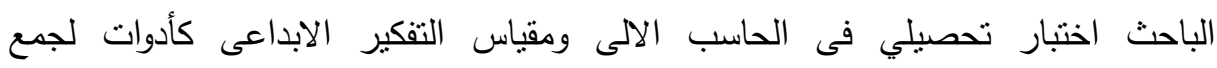

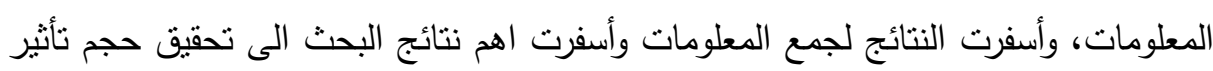
مرتفع فى التحصيل المعرفى لدى طلاب المجموعة التجريبية، وجود فاعلية لإستراتيجية الخرائط الالكترونية فى نتمية التفكير الابداعى لدى الطلاب من خلال درجات عوامل الطلاقة

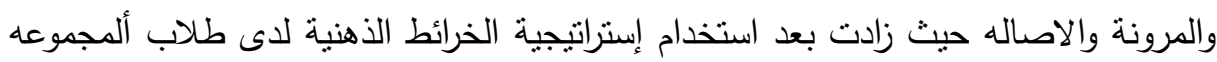
التجربيية و الهرونه

\section{المعالجة التجريبية للبحث وإجراء|ته:}

أولاً: إعداد مواد وأدوات البحث: سارت عملية إعداد الخرائط الذهنية الالكترونية لتتمية المهارات الحياتية البيئية لمعلمي دوى الاحتباجات الخاصة بالإجراءاءت البات التالية:

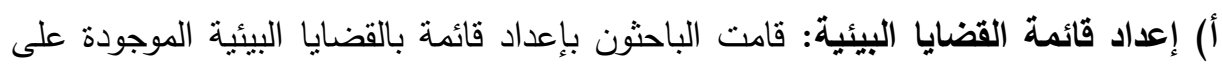
الساحة بصفة عامة ثم عرضها على السادة المحكمين لتحديد أهم القضايا اللازم توفيرها

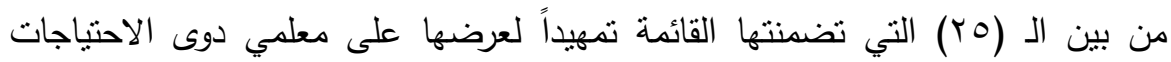

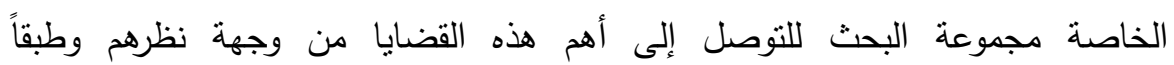
لاحتياجاتهم الفعلية ودرجة أهميتها بالنسبة لهم 
ب)-تصميم بطاقة تحديد احتياجات معلمي دوى الاحتياجات الخاصة من قائمة القضايا والمشكلات البيئية التي تم تحكميها: بعد الانتهاء من إعداد القائمة في صورتها النهائية

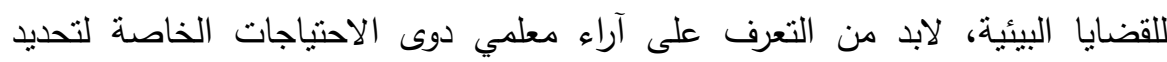

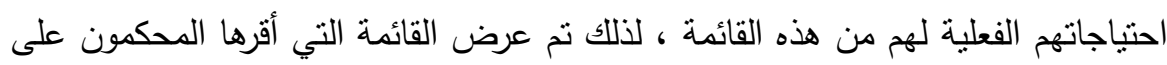
مجموعة بين معلمي دوى الاحتياجات الخاصة العاملين بمدارس محافظة (أسيوط) مقر مراه

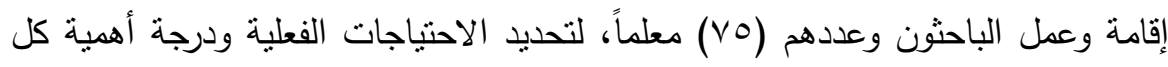
قضية بيئية منها من وجهة نظرهم (كبيرة- منوسطة- ضعيفة)، ثم تم حساب الأوزان

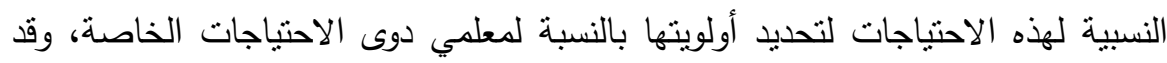
استقر على إلا نقل درجة الأهمية عن 010\% فأكثر كحد أدنى للتعبير عن حاجة المعلم

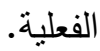

ج) إعداد قائمة المهارات الحياتية البيئية لمعلمي ذوى الاحتياجات الخاصة: قامت الباحثون بإعداد قائمة بالمهارات وذللك وفقاً للخطوات التالية: 1- تحديد الهدف من القائمة:استهدفت القائمة تحديد مهارات الحياتية البيئية. Y- تحديد مصادر اثتقاق القائمة:تم اشتقاق القائمة من مصادر متعددة منها: •مراجع وأدبيات البحث حول المهارات الحياتية البيئية. • البحوث والدراسات السابقة التي تتاولت المهارات الحياتية البيئية.

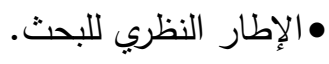

د) تحديد المهارات الحياتية البيئية المتضمنه بالقضايا والمشكلات البيئية المحددة: نم تحليل المشكلات البيئية (المشكلات الغذائيه)،(المشكلات الصحية)، (المشكلات الوقائية) ، ثم بـاتيه حددت الباحثون المهارات الحياتية البيئية المرتبطة بهذة المشكلات وذلك فى ضوء التهات الأهداف المهارية لكل مشكلة بيئية ، المرتبطة بمهارة حل المشكلات ، واقتراح حلول لها.

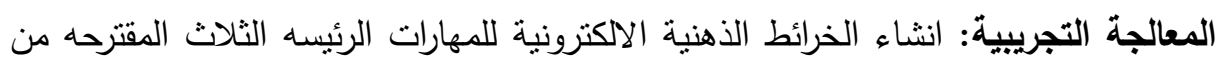
تصميم الباحثون. 
قامت الباحثون باستخدام برامج6 Edraw Mind mape , لتحويل الموضوعات

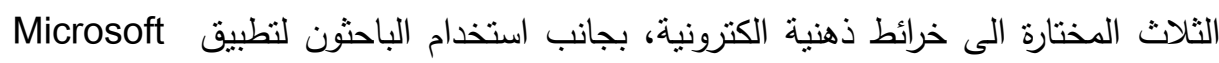
office powerpoient للعرض المنسلسل لأجزاء المحتوى أثناء التدريس فى كل محاضرة

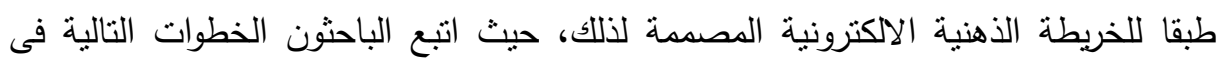
تصميم الخرائط الالكترونية قبد البحث: البهن

1- قامت الباحثون بتحديد الموضوع الرئيسي ( محور الاهتمام ) لكل موضوع من لئن الموضوعات المختارة.

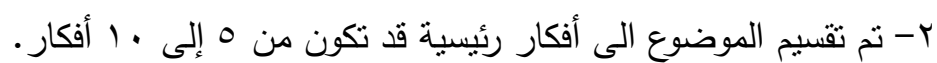

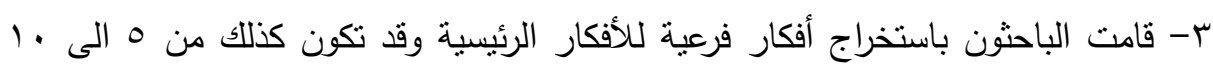

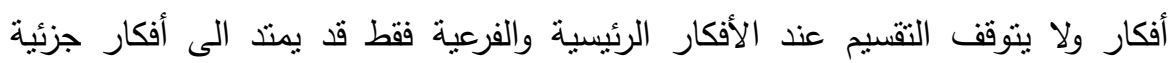
للأفكار الفرعية والافكار الجزئية يخرج منها أفكار اقل حجما وهكذا.

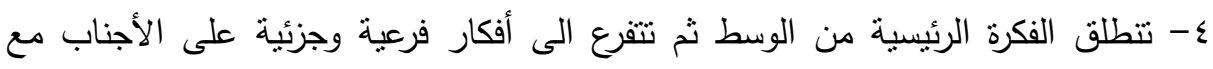
التأكيد على ان الفروع تشكل هيكل متصل بالموضوع الرئيسي . ه- يتم تسليط الضوء على الكلمات المفتاحية لكل موضوع وهى على عبارة عن كلمات و و أفعال قوية .

7 - قامت الباحثون باختيار ألوان وتثكيلات ورسومات تميز الأفكار الرئيسية عن الأفكار الفرعية وتقريعاتها طبقا للميزات والامكانيات المزود بها البرنامج الالكتروني المستخدم لرسم

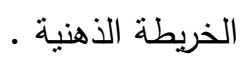

V- قامت الباحثون بإرفاق صور وأثنكال وفيديوهات لتوضيح أفكار رئيسية او فرعية على القي

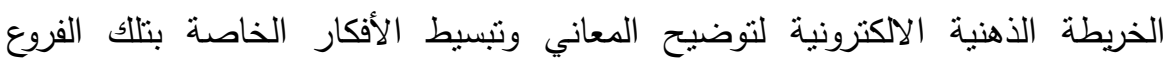

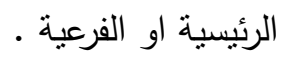

1- قامت الباحثون باستخدام 2007 powerpoient Microsoft office للعرض المتسلسل للخرائط الذهنية المصممة اثثاء التدريس للتخلب على عدم إمكانية العض المنسلسل فى برامج الخرائط الذهنية الاككترونية المتاحة .

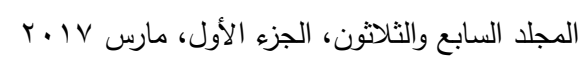


9- قامت الباحثون بعرض مجموعه من الخرائط الذهنية الالكترونية التى قامت بتصميمها

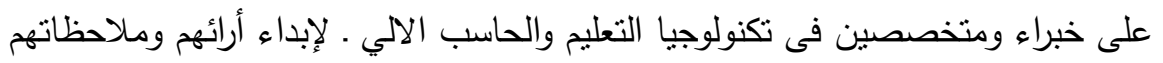
عليها فيما يخص الأساس التكنولوجي التى بنيت علية تصميم الخرائط الذهنية الالكترونية.

• ا- قامت الباحثون بتدريس الموضوع الاول باستخدام الخرائط الذهنية الاككترونية على

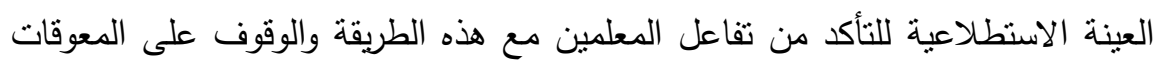
التى يمكن ان تقلل من فاعلية استخدامها فالتدريس. تم اعادة صياغة المهارات المختارة لكي يتم تدريسها باستخدام الخرائط الذهنية، ثم تم

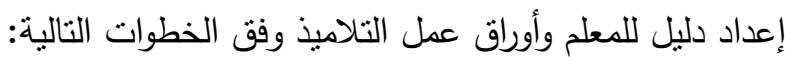

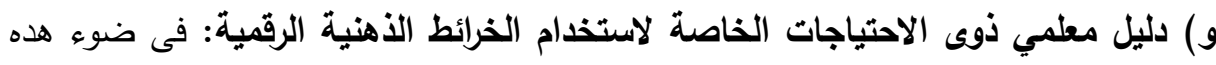

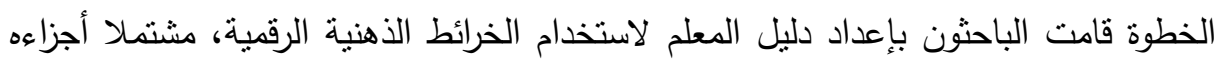
قامت الباحثون بإعداد دليل للمعلم للموضوعات المقترحه ويشتمل الدليل على الآتى: 1-مقدمة يتعرف من خلالها المعلم على ماهية الخرائط الذهنية الإكترونية، وماهية المهارات البيئية الحياتية، ومميزات اكتساب نللك المهارات بالنسبة للمعلم ذوى الاحتباجات الخاصة سواء فى تلك المهارات أو فى مواقف حياتية، كذلك توضح المقدمة للمعلم أهمية الدليل الذى بين يديه وأنه يمده بكل المعلومات التى يحتاج إليها.

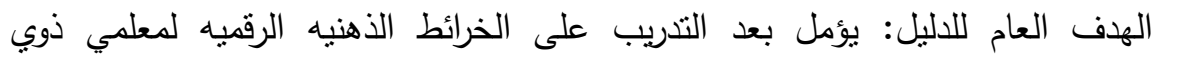

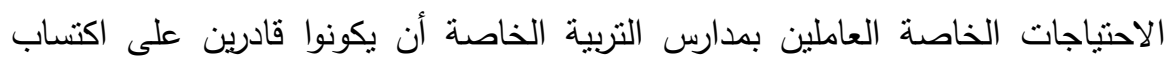
المهارات الحياتيه للتعامل مع المشكلات البيئة. وتم تحديد مجموعة من الأهداف الفرعية التي تخص المعلم لمساعدته علي تقبل فكرة العمل بالخرائط الذهنية الإلكترونية، وأيضا لتوضيح أهمية البحث الحالي، وفيما يلي هذه

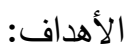


التعرف على القدرات العقلية الذهنية التي يمتلكها العقل البشري وكيفية توظيفها في التعليم والتعلم. • التعرف على الطريقة الفعالة التي يستخدمها العقل البشري في التفكير.

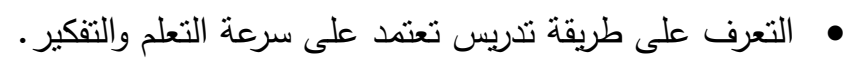
• تتمية المستويات العليا من التحصيل مثل التحليل والتركيب والابداع عن طريق استخدام الخرائط الذهنية الالكترونية سواء الجزئية او الكلية، وعدم الاقتصار على التذكر والحفظ

فقط. • التعرف على اثكال بعض النماذج للخرائط الذهنية سواء اليدوية او الإكترونية • التعرف على بعض الخرائط الذهنية المعدة من قبل الباحثون لتتميه المهارات الحياتيه البيئيه • موضوعات الدليل: • خريطة ذهنية عن المهارات الحياتيه البيئيه في حياتتا اليومية ، خريطة كلية. خريطة ذهنية عن المهارات الغذائيه خريطة جزئيه. خريطة ذهنية عن المهارات الصحيه خريطة جزئيه. خريطة ذهنية عن المهارات الوقائيه خريطة جزئيه. ץ- ملف التخزين السحابى المستخدم. r- إرشادات للمعلم بشأن تدريس الموضوعات المتضمنة. ع - الخطة الزمنية المقترحة لتدريس الموضوعات المنضمنة.

0-خطة درس لكل موضوع من الموضوعات المنضمنة يتضح بها الأهداف السلوكية الخاصة بكل موضوع وخطوات سير الدرس وطرق التدريس والوسائل التعليمية الخاصة بكل موضوع. ד- قائمة مراجع لكل درس. 
ي) أولق عمل الطلاب: قامت الباحثون بإعداد أوراق عمل الطلاب، يقوم الطلاب بأداء الأنشطة والتكليفات طول فترة التنفيذ بعد كل درس والتي تعكس مدى تفاعله مع المعلم.

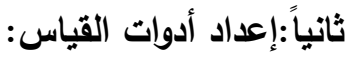

الأداة الأولىى: إعداد مقياس المهارات اليئية لمعلمي دوى الاحتياجات الخاصة: فيما يلى إلى عرض لخطوات إعداد مقياس المهارات الحياتية البيئية وضبطهما وإجراءات تطبيقهما. • تحديد الهدف من المقياس: يهدف هذا المقياس إلى قياس مدى نمو المهارات الحياتية البيئية لاى معلمي دوى الاحتياجات الخاصة (مجموعة البحث) للمهارات الحياتية البيئية التي وردت بموضوعات الخرائط الذهنية الرقمية. • إعداد وصياغة مفردات المقياس: إعداد وصياغة مفردات وصياغة مقياس المهارات البيئية للمعلمين، وذللك بعد الإطلاع على البحوث والدراسات السابقة التي تتاولت إعداد مقاييس المهارات الحياتية البيئية والثروط الواجب نوافرها في المقياس تكون مقياس المهارات من ثلاث أجزاء مستقلين وهما: م الجزء الأول: تحديد وإدراك المشكلات البيئية . . م الجزء الثاني: تتظيم المعلومات والبيانات حول هذه المشكلات. م الجزء الثالث: اقتراح الحول البديلة للشكلات البيئية. القسم الأول:- تحسب وإدرلك المشكلات البيئية: ويهدف إلى قياس قدرة معلم ذوى الاحتياجات الخاصة على تحديد وإدراك المشكلات البيئية وقد نم صباغتها فى صورة مواقف يعرض كل منها مشكلة بيئية، عن طريق قراءة الموقف وتحديد المشكلة البيئية النى يعرضها الموقف، مهنه ويتكون من (11) موقفاً، يعطى لكل مفردة درجة واحدة عدد تحديد المشكلة، أو صفر فى دئ

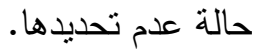
القسم الثانسي:-تنظيخ المعلومات والبيانات للمشكلة: ويهدف إلى قياس قدرة معلم ذوى الاحتباجات الخاصة على تتظيم المعلومات والبيانات والملاحظة، وقد تم صباغته من مجموعة من العبارات التى تتعلق ببعض الموضوعات والمشكلات البيئية التى تضنها

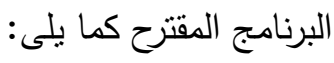


ويوضح الجدول التالى أرقام الأسئلة الواردة فى القسم الثانى من المقياس وعددها (1 (l) فى مقياس المهارات البيئية

القسم الثالث:- اقتراح طظول للمشكلات البيئية: ويهدف إلى قياس قدرة معلم ذوى الاحتياجات الخاصة على اقتراح حلول للمشكلات البيئية، وقد تم صياغته المفردات فى مجموعة من البئن العبارات والمواقف نمنل كل منها مشكلة بيئية ويقوم المعلم بإقتراح حلول مناسبة لكل مشكلة، ويتكون من (1) مشكلة بيئية، وفى حالة أن يقدم المعلم أكثر من حل يحصل على دئل درجة

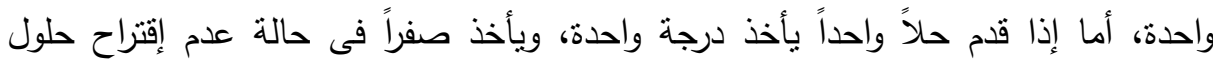
ل اللمشكلة.

وقد تم عرض المقياس فى صورته المبدئية على مجموعة من المحكمين فى مجال التربية البيئية، والمناهج وطرق التدريس وتكنولوجيا التعليم لأخذ آرائهم من حيث مدئ منى مناسبة منية

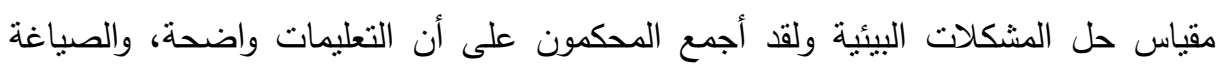

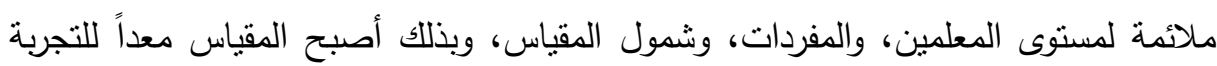
الاستطلاعية

• إجراء التجربة الاسنطلاعية لمقياس المهارات البيئية لمعلى ذوى الاحتباجات الخاصة:

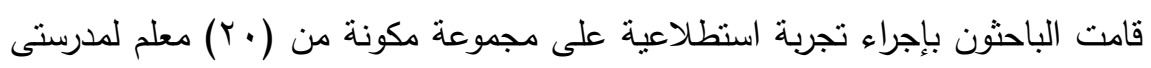
الامل بنين وبنات للصم والبكم بأسيوط وذللك بهدف: • تحديد زمن المقياس: قامت الباحثون بحساب الزمن اللازم لأداء المقياس، حيث قامدام بتطبيق المقياس على مجموعة التجربة الاستطلاعية وتوصلت إلى الزمن اللازم للانتهاء

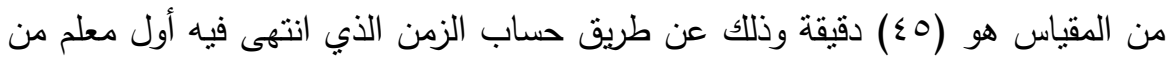

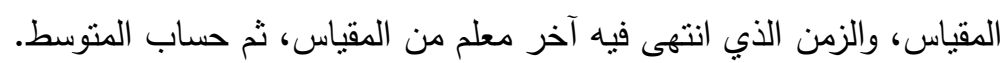
• صدق المقياس: ويقصد به أن المقياس يقيس بالفعل ما وضع لقياسه، وقد قامت التهن الباحثون بعرض المقياس على مجموعة المحكمين ،حيث أكدت آراؤهم أن مقياس المهارات الحياتية

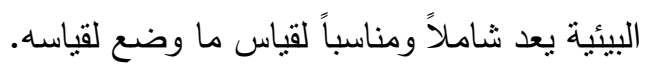


• حساب ثبات المقياس: ويقصد بثبات المقياس أن يحصل المعلم على نفس النتائج إذا ما أعيد عليه نفس المقياس في نفس ظروف التطبيق الأول، ولحساب ثبات المقياس قامت

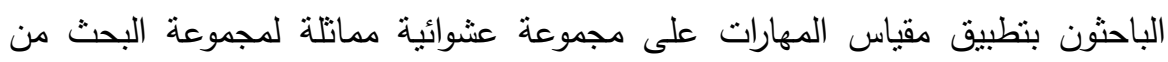

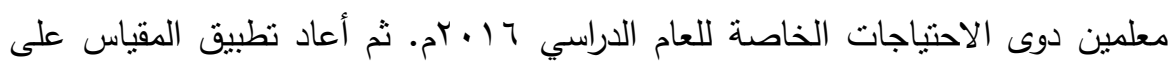
نفس مجموعة المعلمين وذلك بعد مرور أسبوعين من تاريخ التطبيق الأول وبتطبيق معادلة

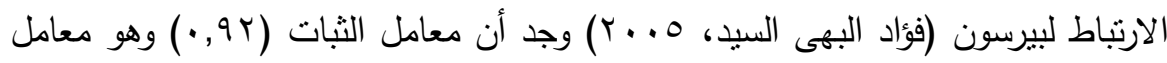

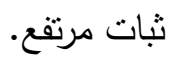

الأداة الثانية: "بطاقة ملاحظة السلوك البيئحى للطالب: تم وضع بطاقة ملاحظة السلوك البيئي بناءاً على قائمة القضايا والمشكلات البيئية حيث تم إعداد البطاقة وفقا الخطوات الآتية: 1 - تعليـ الهيف من وضع البطاقة: يشتمل الهدف الأساسي لوضع البطاقة في قياس السلوك البيئي الفعلي للطالب من خلال تعامله مع البيئة المحيطة

أب - إعداد الصورة الأولية للبطاقة: من هلبة

أ- نم تحديد الأبعاد الأساسية للمواقف السلوكية البيئية التي تقيسها البطاقة وفقاً للأبعاد الرئيسة

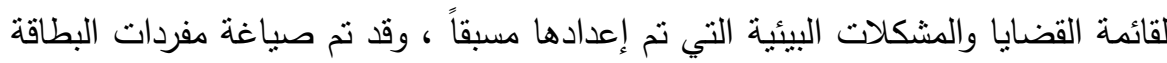
من خلال إدراج مجموعة من المواقف السلوكية البيئية التي قد بمارسها الطلاب أثناء

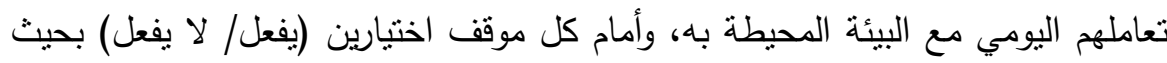
يمنح درجة واحة عن (يفعل) وصفر عن (لا يفعل) وسوف يتم تسجيل مدى ممارسة ملاس الطالب للسلوك من خلال الملاحظ المكلف بذلك. ب- تم وضع الصورة الأولية لبطاقة ملاحظة السلوك البيئي على (·r) موقف لفظي توضح بعض السلوكيات البيئية التي قد يمارسها الطالب أثناء تعامله المباشر مع البيئة.

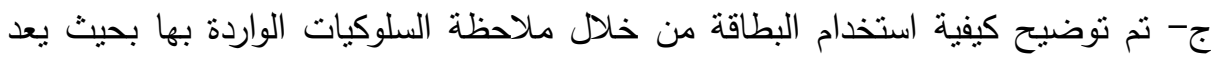
قيام الطالب بتتفيذها دليل على توافرها ويعد غيابها دليل على عدم توافرها.

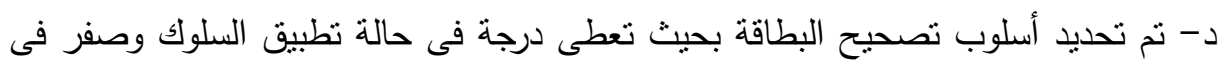

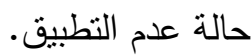


ب- التأكل من مناسبة البطاقة:

أ- نم عرض البطاقة على لجنة من المحكمين وهم نفس لجنة محكمين المقياس، وذللك للتأكد من صلاحيتها من حيث: ه انتماء كل موقف سلوكي للبعد الذي ورد ضمنه من أبعاد الابعاد البيئية الواردة فى قائمة القضايا والمشكلات البيئية المعدة مسبقاً. • صحة مفردات المواقف من الناحية العلمية واللغوية. • إضافة أو حذف ما برونه مناسباً في مواقف البطاقة وقد أجمع المحكمين على مدى شمولية البطاقة لقياس السلوك البيئي الفعلي لدى الطالب، كما أبدى بعضهم ملاحظات حول إعادة إنها صياغة بعض المواقف واستبعاد بعضها، وفى ضوء ملاحظاتهم نم تعديل البطاقة فأصبح

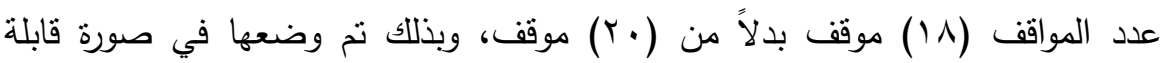
للنطبيق المبدئي على الطلاب. ب- تم التأكد من ثبات البطاقة حيث طبقت على نفس المجموعة النى طبق عليهم اختبار

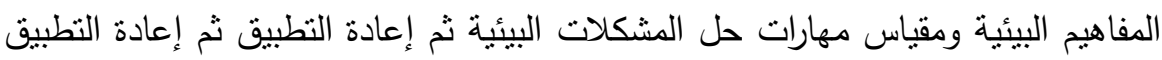
بعد أسبوعين وبحساب معامل الارتباط بين التطبيقين باستخدام معامل بيرسون وكانت

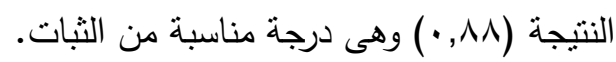

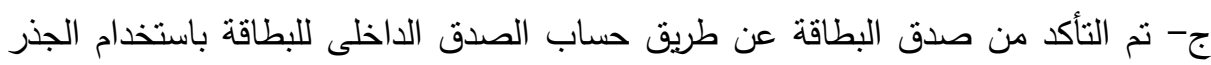

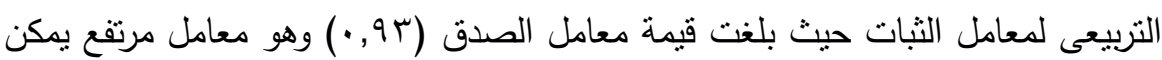

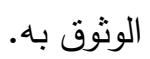

د- نم تحديد طريقة التصحيح للبطاقة وفقاً للأبعاد الرئيسية لقائمة القضايا والمشكلات البيئية، وذللك بإعطاء درجة لنطبيق السلوك وصفر لعدم التطبيق. ع- وضع البطاقة في صورتها النهائبة: بعد عرض البطاقة على لجنة من المحكمين وإجراء التعديلات والإضافات المقترحة، وحساب ثناتها وصدقها، أصبحت فى صورتها النهائية القابلة

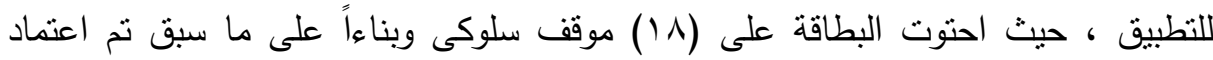


أدوات القياس ووضعها موضع التطبيق لقياس فاعلية استخدام الخرائط الذهنية الرقمية لتتمية المهارات الحياتية البيئية لاى معلمي ذوى الاحتياجات الخاصة وأثر ذلك على الطلاب.

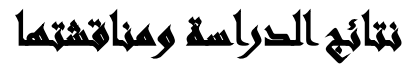

أولاً: التكافؤ بين المجموعتين الضابطة والتجريبية: للتحقق من تكافؤ المجموعتين نفترض أنه" لا توجد فروق ذات دلالة إحصائية بين منوسطات درجات أفراد المجموعتين الضابطة والتجريبية في التطبيق القبلي لمقياس المهارات الحباتية البيئية لدى معلمي ذوي

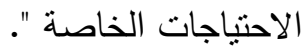

وللتأكد من صحة هذا الفرض استخدمت الباحثون اختبار ت للأزواج المستقلة من خلال البرنامج الاحصائي Spss، وذللك لمعرفة الفروق بين متوسطات درجات أفراد المجموعتين الضابطة والتجريبية في النطبيق القبلي لكقياس المهارات الحياتية البيئية لدى معلمي ذوي الاحتياجات الخاصة وجدول( (1) يوضح ذلك. جدول(1): المتوسط الحسابي والانحراف المعياري وقيمة ت للفروق بين درجات أفراد المجموعتين الضابطة والتجريبية في النطبيق القبلي

\begin{tabular}{|c|c|c|c|c|c|c|c|}
\hline مستوي & قيمة t & الالمعراف & المستوسطي & الحرية & العدد & المجموعة & الأبعاد \\
\hline \multirow{2}{*}{ غند ا., عال. } & \multirow{2}{*}{$\cdot, A V Y$} & $\varepsilon, T \wedge \varepsilon \cdot Y$ & $17, Y \varepsilon \ldots$ & rq & $r$. & ضابطة & \multirow{2}{*}{ مقياس المهارات } \\
\hline & & $0,70 Y \cdot r$ & $1 \varepsilon, 97 \ldots$ & rq & $r$. & تجريبية & \\
\hline \multirow{2}{*}{ غند ا., ع. } & \multirow{2}{*}{$\cdot, \cdot \wedge \mathrm{V}$} & $1, \vee \vee \vee 901$ & $r, \varepsilon \ldots$ & rq & $r$. & ضابطة & \multirow{2}{*}{ البعد الأول } \\
\hline & & $1, \varepsilon V \leqslant Y r$ & $r, \varepsilon \varepsilon \ldots$ & rq & $r$. & تجريبية & \\
\hline \multirow{2}{*}{ 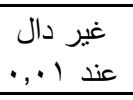 } & \multirow{2}{*}{$1, V Y$} & $1,9 r 9 \cdot V$ & Y,OY... & rq & $r \cdot$ & ضابطة & \multirow{2}{*}{ البعد الثاني } \\
\hline & & $1, r \vee 0 \leq 1$ & $1, V Y \ldots$ & rq & $r$. & تجريبية & \\
\hline \multirow{2}{*}{ غند ا..,. } & \multirow{2}{*}{., 17} & 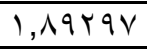 & $r, \varepsilon \ldots$ & rq & $r$. & ضابطة & \multirow{2}{*}{ البعد الثالث } \\
\hline & & 1,7roN & r,rY.. & rq & $r$ & تجريبية & \\
\hline
\end{tabular}

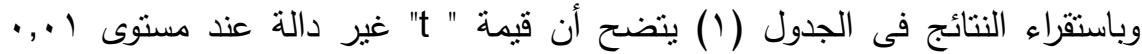

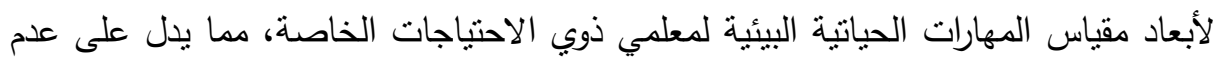
وجود فروق جوهرية بين متوسط درجات المجموعتين الضابطة والتجريبية في التطبيق القبلي، وذللك يدل على التكافؤ بين أفراد المجموعتين. 


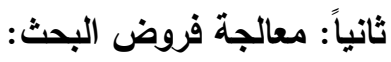

الفرض الأول وينص على أنه" توجد فروق ذات دلالة إحصائية بين متوسطات درجات أفراد

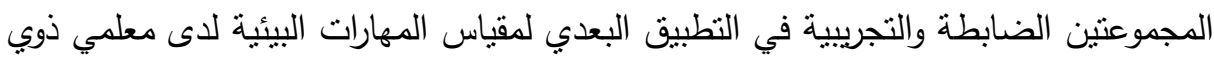
الاحتياجات الخاصة وذلك لصالح التطبيق البعدي". للتحقق من صحة هذا الفرض استخدم الباحثون اختبار ت للأزواج المستقلة من خلا لـأل البرنامج الاحصائي Spss، وذلك لمعرفة الفروق بين منوسطات درجات أفراد المجموعنين

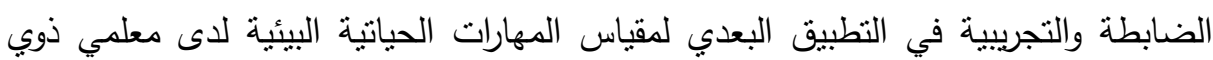
الاحتباجات الخاصة وجدول(r) يوضح ذللك. جدول(r): المتوسط الحسابي والانحراف المعياري وقيمة ت للفروق بين درجات أفراد

\begin{tabular}{|c|c|c|c|c|c|c|c|}
\hline الدلالةي & قيمة t & المعياري & الحستابي & الحرجاتة & العداد & المجموعة & الأبعاد \\
\hline \multirow[b]{2}{*}{ دال, ال. عند } & \multirow[b]{2}{*}{$17,9 V$} & $\varepsilon, T \wedge \varepsilon \cdot r$ & $17, Y \leq \ldots$ & rq & $r$. & ضابطة & \multirow{2}{*}{ البيئية } \\
\hline & & $\varepsilon, \Gamma \wedge \vee \varepsilon \wedge$ & $r \vee, \wedge \ldots$ & rq & $r$. & تجريبية & \\
\hline \multirow{2}{*}{$\begin{array}{c}\text { دال ع.,. } \\
\end{array}$} & \multirow{2}{*}{$|\leq, \Gamma|$} & $1, \vee \vee \vee 901$ & $r, \varepsilon \ldots$ & rq & $r$. & ضابطة & \multirow{2}{*}{ البعد الأول } \\
\hline & & $1, \vee \vee \vee 901$ & $9,7 \ldots$ & rq & $r$. & تجريبية & \\
\hline \multirow{2}{*}{ 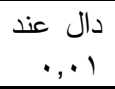 } & \multirow{2}{*}{$1 \Gamma, 11$} & $1,9 \mu 9 \cdot v$ & r,OY.. & rq & $r$. & ضابطة & \multirow{2}{*}{ البعد الثاني } \\
\hline & & $1, \leqslant \wedge 0 \leqslant 9$ & $\Lambda, 97 \ldots$ & rq & $r$. & تجرييية & \\
\hline \multirow{2}{*}{ 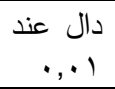 } & \multirow{2}{*}{ IT,OV } & 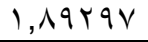 & $r, \varepsilon \ldots$ & rq & $r$. & ضابطة & \multirow{2}{*}{ البعد الثالث } \\
\hline & & $1,0 r \cdot \Lambda$. & $\Lambda, 0 Y \ldots$ & rq & $r$. & تجريبية & \\
\hline
\end{tabular}

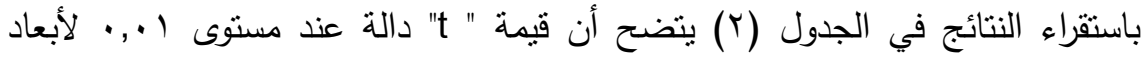
مقياس المهارات الحياتية البيئية لمعلمي ذوي الاحتياجات الخاصة لصالح منوسط درجات أفراد

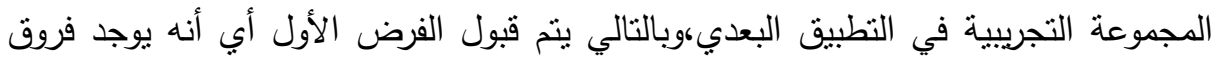
جوهرية بين متوسط درجات أفراد المجموعتين المجموعة الضابطة التي تستخدم (الطريقة التقليدية)، ومتوسط درجات أفراد المجموعة التجريبية التي تستخدم (الخرائط الذهنية الرقمية) في القياس البعدي لمقياس المهارات الحياتية البيئية لصالح المجموعة التجريبية،وجاءت دربه هذه

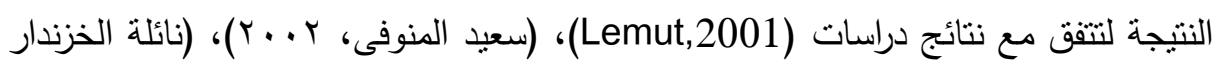




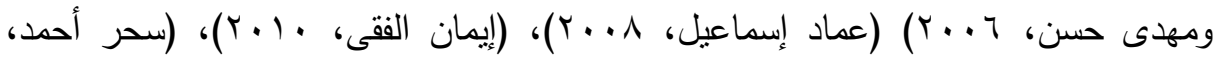

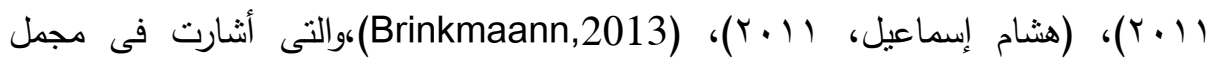

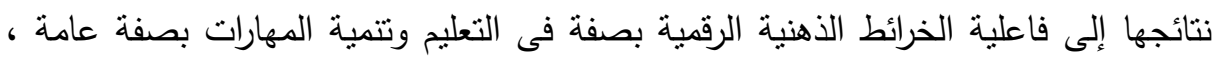
ويمكن تقسير هذه النتيجة على ضوء النظرية البنائية التي تشكل ضابطاً لعمل الخرائط الذهنية الرقمية وتؤكد على أن المتعلم عند استخدامه لانظمة الخرائط الذهنية الرقمية فيشعر بملكيته لهنه لنظام التعلم مما يدفعه نحو النشاط المستمر داخل النظام من أجل بناء معارفه بشكل منفرد

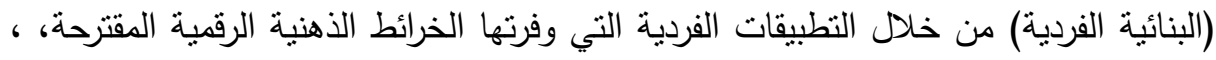
وهو ما انعكس على المتعلمين ودفعهم نحو خلق ممارسات تعزز تعلمهم من خلال ممارسة

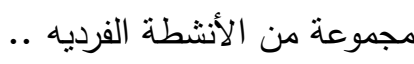
فضلاً عن ذلك فإن تطبيقات الخرائط الذهنية الرقمية قد سمحت للتتعمين الإكثار من عرض الأمثلة والنماذج لنتشيط عمليات الاستدلال والاستقراء من خلال ما وفرته الخرائط

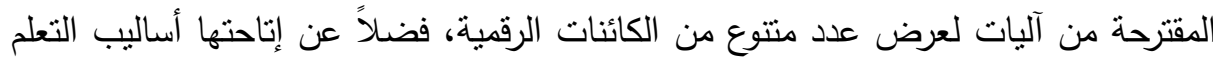
النشط منل العصف الذهنى Brain Storming من خلال الانشطة المرتبطة بها ، فإن ذلك الك قد أناح الفرص للمتعلم لتتميه المهارات الحياتية البيئية، كذلك فقد سمت تطبيقات الخرائط المقترحة للمتعلمين بالتعليق وإبداء آرائهم دون خوف أو خجل وهو ما كان له دوراً كبيراً في

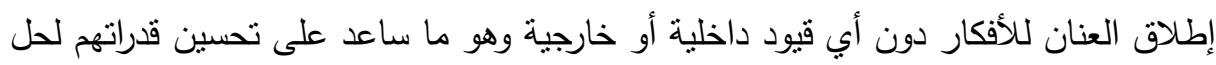

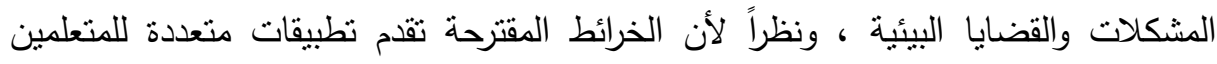
تسمح بإجراء معالجات تحريرية للصور الثابتة والمتحركة فإن ذللك فد أتاح للمتعلمين المران على تطوير أفكارهم واختبارها من خلاء المصورات المختلفة داخل البيئة، كذلك لأن الخرائط يمكن الدخول إليها واستخدامها في أبي وقت دون قيود مرنبطة بالزمان والمكان أو الأجهزة

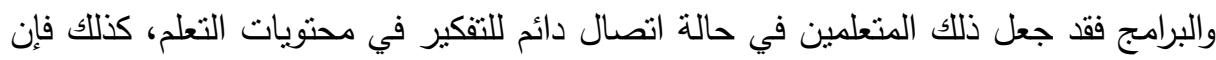
التتوع الكبير في كائنات التعلم التي تحتويها الخرائط ساعد المتعلمين على إثراء أفكارهم وتطويرها، وهو ما ساعد في النهاية على تتمية المهارات الحياتية البيئية لديهر. 
الفرض الثانى وينص على أنه" توجد فروق ذات دلالة إحصائية بين متوسطي درجات الطلاب

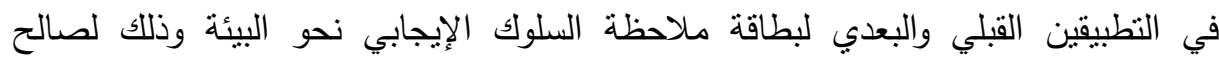

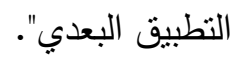

للتحقق من صحة هذا الفرض استخدمت الباحثون اختبار ت للأزواج المرتبطة من خلال البرنامج الاحصائي Spss، وذلك لمعرفة الفروق بين منوسطي درجات الطلاب في التطبيقين القبلي والبعدي لبطاقة ملاحظة السلوك الإيجابي نحو البيئة وجدول(ب) يوضح ذلانك. جدول(ץ): المتوسط الحسابي والانحراف المعياري وقيمة ت للفروق بين متوسطي درجات الطلاب في النطبيقين القبلي والبعدي لبطاقة ملاحظة السلوك الإيجابي نحو البيئة

\begin{tabular}{|c|c|c|c|c|c|c|c|}
\hline الدستوية & قيمة t & الانحرياري & الحستوسي & الحرجية & العدد & التطبيق & المقياس \\
\hline \multirow{2}{*}{$\begin{array}{l}\text { دال } \\
\text { د., } \\
\text { د., }\end{array}$} & \multirow[b]{2}{*}{$1 Y, 04$} & r,or^q1 & 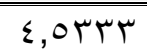 & rq & r. & قبلي & \multirow{2}{*}{ السلوكاحظة البئي } \\
\hline & & $r, \vee q q .1$ & $\mid r, \varepsilon \ldots$ & rq & $r$. & بعدي & \\
\hline
\end{tabular}

يتضح من جدول(r) أن قيمة " t" دالة عند مستوى l.,., للفرق بين التطبيقين القبلي والبعدي لبطاقة ملاحظة السلوك الإيجابي نحو البيئة، مما يدل على وجود فروق جوهرية بين متوسط درجات الطلاب لصالح التطبيق البعدي، ويتضح التحسن الدى طرأ على أداء الطلاب

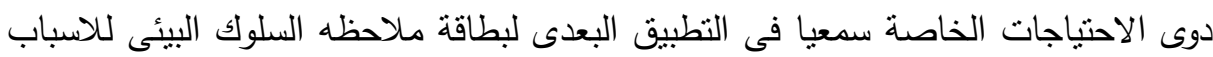
التاليه: - (النيه - توظيف لغة الاشارة فى الخرائط الذهنية الرقمية بشكل مقنن راعى الميول والاحتياجات للطلاب دوى الاحتياجات الخاصة سمعيا وساعدتهم على التعلم. - البساطه فى التصميم بمعايير تكنولوجيه مقننه نتتاسب مع الخصائص الادراكيه والنفسيه للطلاب دوى الاحتياجات الخاصة سمعيا.

الفرض الثالث وينص على أنه" توجد علاقة ارتباطية موجبة دالة إحصائياً بين تتمية المهارات

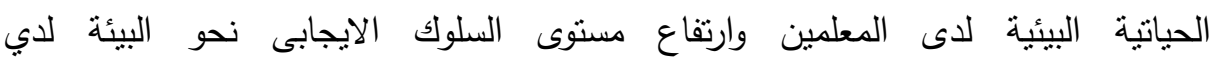
الطلاب".للتحقق من صحة هذا الفرض استخدم الباحثون معامل ارتباط بيرسون من خلال 
البرنامج الاحصائي Spss، وذلك لمعرفة الارتباط والعلاقة بين تتمية المفاهيم والمهارات

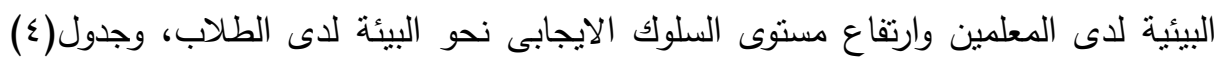
يوضح ذلك. جدول(§): مصفوفة معاملات ارتباط بيرسون بين تتمية المفاهيم والمهارات البيئية لدى

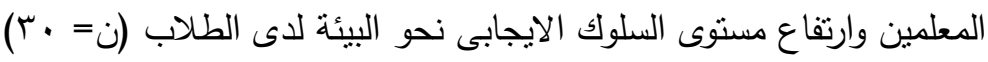

\begin{tabular}{|c|c|c|c|c|c|c|}
\hline الملاحظة & المهارات & الثالثد & الثانيد & الأبعد & المفاهيم & الأبعاد \\
\hline$* *, 9 \cdot \wedge$ & $* * .9 \vee \varepsilon$ & **, , qr & **.AYT & $* * .971$ & - & المهاريات \\
\hline$* *, \wedge \Sigma \wedge$ & ***, $9 \mu \varepsilon$ & ***,人 . & **, , Vro & - & & البعد الأول \\
\hline$* *, 91 \Gamma$ & $* *, \cdot, 9 \cdot 1$ & ***, & - & & & البعد الثانيى \\
\hline$* *, 9 \leq \leqslant$ & ***,97. & - & & & & البعد الثالث \\
\hline$* *, 97 r$ & - & & & & & المفاهبيم \\
\hline - & & & & & & الملاحظة \\
\hline
\end{tabular}

يتضح من جدول(§) أن جميع معاملات الارتباط دالة، وذلك يؤكد وجود علاقة ارتباطية

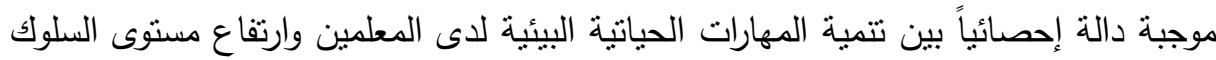
الايجابى نحو البيئة لدى الطلاب، وتتفق هذه النتيجة مع دراسة كلا من ضياء

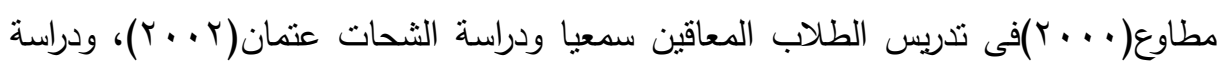

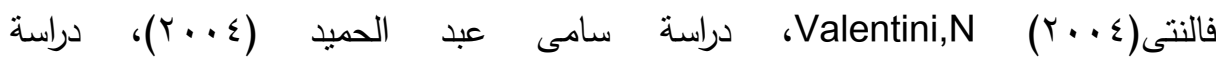

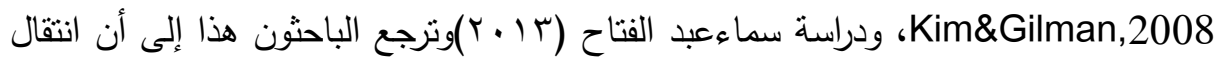
اثز التعلم نتيجة استخدام المعلمين الخرائط الذهنية الرقمية في إكتساب المهارات الحياتية البيئية فالمعلم بربط الطلاب بييئته المحليه ويعرفهم بالقضايا والمشكلات البيئية التى تواجههم

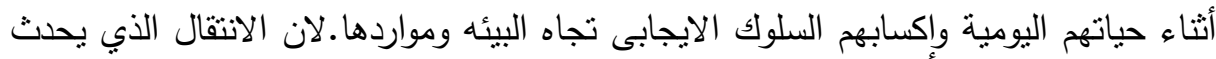

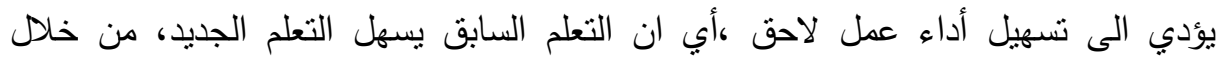

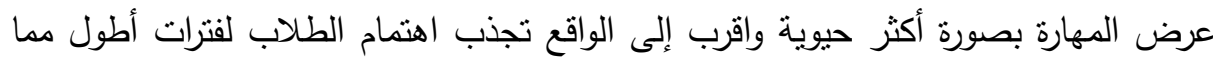
294

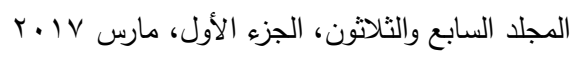


تحدثه الأعمال التقليدية.فالثرح الذى كان يظهر لدى النطبيق باستخدام لغة الإثارة كبديل

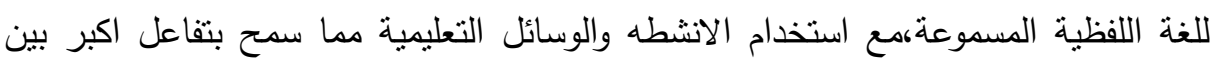
الطلاب والمعلمين، كان له أثز فعال في تعلم الطلاب ذوى الاحتياجات الخاصة سمعيا بأسلوب صحيح، حيث راعت الباحثون خصائص الطلاب المعاقين سمعيا وحاجاتهم التربوية، وساعدهم على التعلم، لعدم وقوعهم فى أخطاء. من خلال نطبيق المهارات الحياتية البيئية

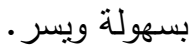

ثالثاً: التحقق من فعالية الخرائط الذهنية الرقمية عن طريق حساب حجم الأثر:

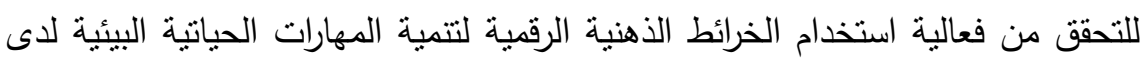
معلمي ذوي الاحتباجات الخاصة وأثز ذلك على الطلاب، استخدمت الباحثون مربع إيتا لحجم الأثز وجدول (0) يوضح ذللك. جدول(ه): قيمة ت ومربع إيتا ومقدار الأثر للفروق بين متوسطي أداء أفراد العينة في

\begin{tabular}{|c|c|c|c|c|}
\hline \multicolumn{5}{|c|}{ التطبيقين القبلي والبعدي } \\
\hline مقدار التأثير & مريع إيتا & مستوى الدلالة & قيمة & الأبعاد \\
\hline كبير & $\cdot, 91$ & دال عند ا.,.• & $17,9 V$ & مقياس المهارات البيئية \\
\hline كبير & $\cdot, \wedge \wedge$ & دال عند ا.,., & $|\varepsilon, \Gamma|$ & البعد الأول \\
\hline كبير & $\cdot, \wedge \mathrm{T}$ & دال عند ا+,. & $1 \%, 11$ & البعد الثانى \\
\hline كبيز & $\cdot, \wedge \varepsilon$ & دال عند ا.,. & $1 Y, O V$ & البعد الثالث \\
\hline كبير & $\cdot, \wedge \varepsilon$ & دال عند ا.,. & $1 Y, 07$ & بطاقة الملاحظة \\
\hline
\end{tabular}

يتضح من جدول(0) أن مقدار الأثر كبير، مما يدل على فعالية استخدام الخرائط

الذهنية الرقمية لتنمية المهارات الحياتية البيئية لدى معلمي ذوي الاحتياجات الخاصة وأثر ذلك

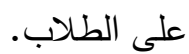

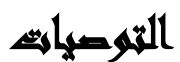

يقترح البحث الحالي في ضوء ما توصلت إليه من نتائج التوصيات والبحوث الآتية: في ضوء نتائج البحث الحالي توصى الباحثنون بما يلي: ا - ضرورة التوجيه نحو توظيف الخرائط الذهنية الرقمية في دعم عمليات التعلم المتتوعة للتلاميذ المعاقين سمعيا. 
r- ضرورة توظيف الخرائط الذهنية الرقمية كبديلاً في حل مشكلات البنية التحتية المرتبطة

$$
\text { بتوظيف التعليم الإلكتروني في المؤسسات التعليمية. }
$$

r- فاعلية استخدام الخرائط الذهنية فى تتمية مهارات التفكير البصرى لدى لإنى التلاميذ المعاقين

ـ - تدريب أعضاء هيئة التدريس والطلاب على نوظيف الخرائط الذهنية الرقمية في عمليات

التعلم لمهارات حل المشكلات والقضايا البيئية.

\section{2all}

نجيب الرفاعى : الخريطة الذهنية خطوة خطوة، الكويت، مطابع الخط، 7 . . ץ م.

http://emeg.mans.edu.eg/index.php?page=news\&task=show\&id=256

إيمان سليم الفقى(· • (Y): أثر استخدام إستراتيجية تدريسية قائمة على القبعات الستة

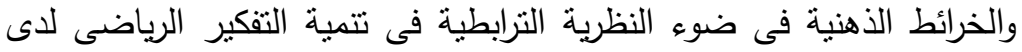

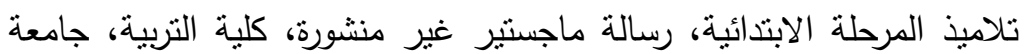

طنطا.

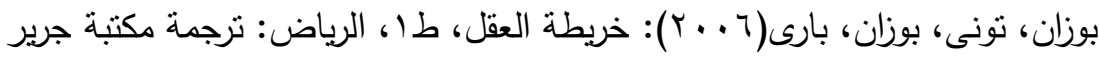

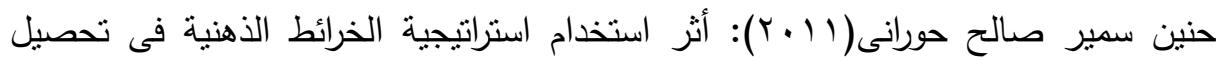

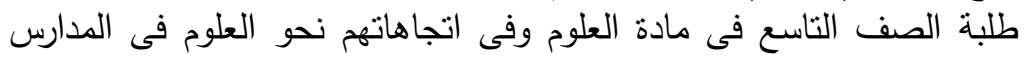

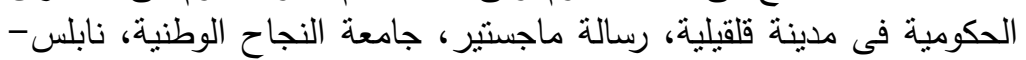

$$
\text { فلسطين. }
$$

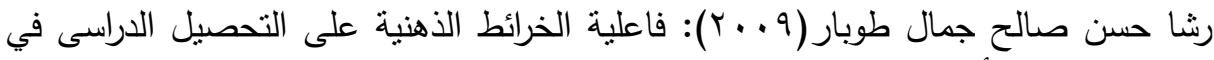

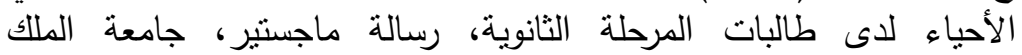

$$
\text { عبدالعزيز · مداء }
$$

سحر عبداله محمد أحمد(1 ( • ؟): فاعلية استخدام الخرائط الذهنية المعززة بالوسائط المتعددة

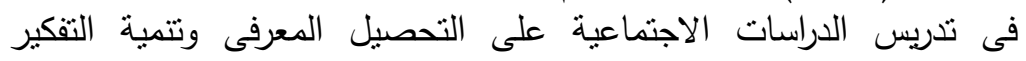
الاستدلالى لاى تلاميذ المرحلة الإعدادية، رسالة ماجسنير غير التهير منشورة، كلية

$$
\text { التربية جامعة سوهاج. }
$$

$$
\text { المجلد السابع والثلاثون، الجزء الأول، مارس VI. T }
$$




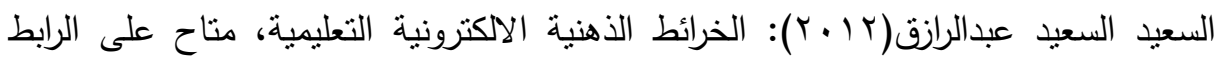
التالى:

سعيد المنوفى: فعالية المدخل المنظومى فى تدريس حساب المنلات وأثنىه على التفكير

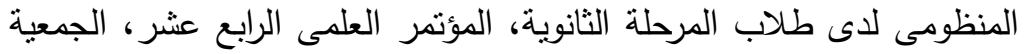

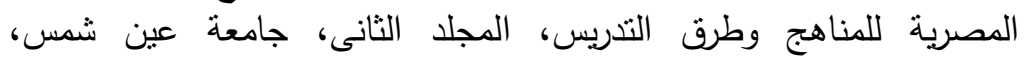

$$
\text { Orيوليو r... }
$$

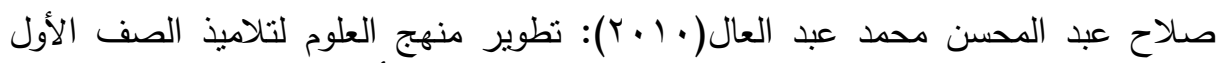

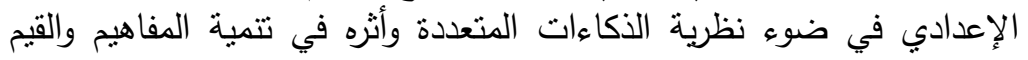

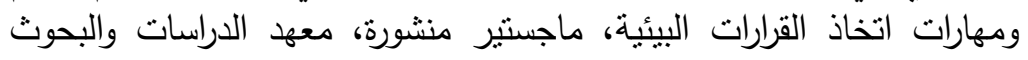
البيئية، جامعة عين شمس.

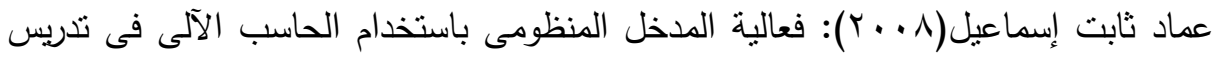

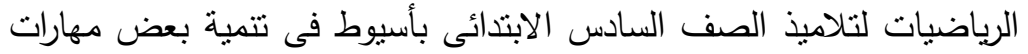
التقكير المنظومى ومهارات اتخاذ القرار، رسالة دكتوراه غير لأنير منشورة، كلية بعنية التربية، جامعة المنيا

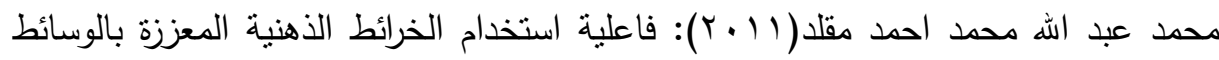

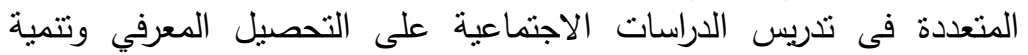

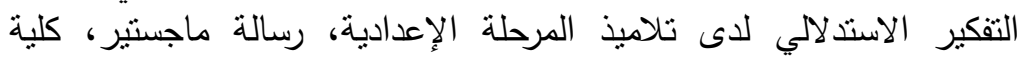
التربية، جامعة سوهاج منى الحديدي وجمال الخطيب(0 . . ץ): استراتيجيات تعليم الطلبة ذوبي الحاجات الخاصة، دار

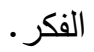

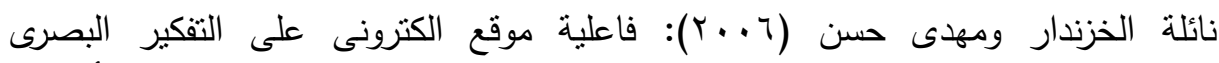

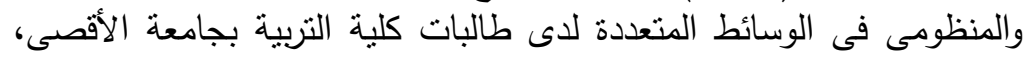

$$
\begin{aligned}
& \text { المؤتمر العلمى الثنامن عشر "مناهج التعليم وبناء الإنسان } \\
& \text { يوليو بدران الضيافة- جامعة عين شمس العباسية العربى، القاهرة. }
\end{aligned}
$$

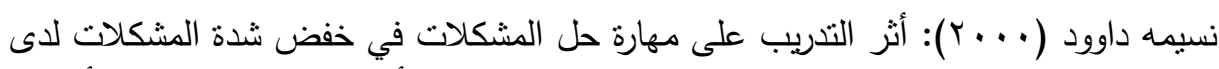

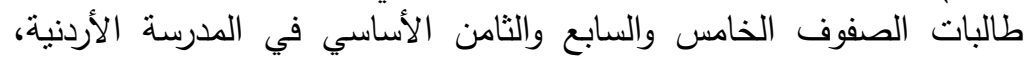

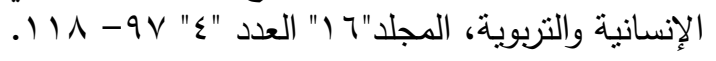

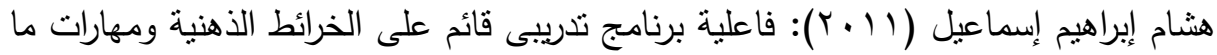

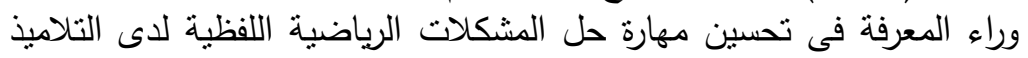

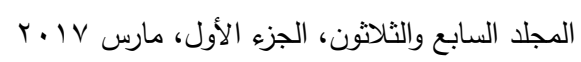




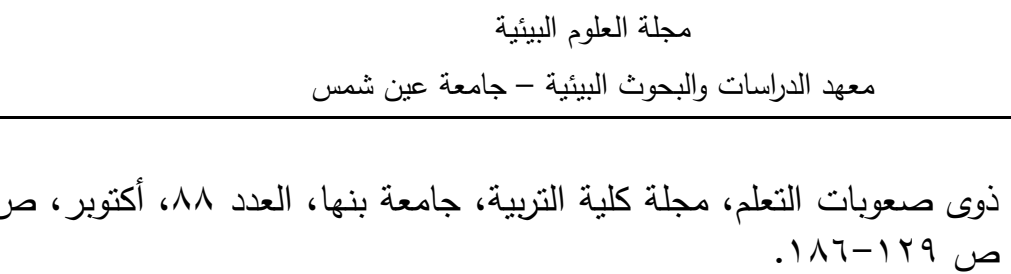

Anthony V D'Antonil, Genevievc Pinto Zipp, Valerie G Olsonl, Terrcnce F Cahilll(2010): Docs the mindmap learning strategy facilitate, Availabl athttp://link, springcr.com/content/pdf/10. 1186\%2F1472-6920-1061.pdf.

Willis , Chery \& Miertschin, Susan .(2006). Mind Maps as Actiye Learning, Journal of Computing Sciences Colleges, 21(4) Electronc Journal for the Integration of Technology in Education, Vol. 1,No. 1,2001.

Donald F.Moores(1996):"Educating the Deaf,Psychology,Principles and Practices and Practices",4th ed.,Boston,Toronto.Houghton Mifflin Company.

Elisabeth H.Wiig\&Jane E.Neurman(1997):"The Selection of visual Dinensions by Deaf and Hearing Children"American Annals of the Deaf,Vol. 117,No.3, Jun, 1997.

Lewis,R.B\&Doonlag,D.H(1995):"Teaching special Students in the Mainstream"4th ed.,New Jersey,Prentice - Hall,Inc. Englewood Cliffs.

Bnnkmaan, Astrid (2013) : Mind Mapping as a Tool in Mathematics Education, National Council of Teachers of Mathematics Stable The Mathematics Teacher, Vol. 96, No. 2, pp. 96101.

Kim,Daesang\&Gilman,David(2008):"Effects Text,and Graphic Aids in Multimedia Instruction for VocabularyLearning", Education Technology\&Society, Vol.11, No.3.

Elicia L. Pollard(2010): Meeting The Demands of Confessional Education : A Study of Mind Mapping in Professional Doctoral Physical Therapy Education Program, Capella University

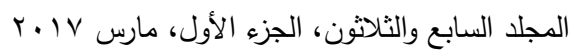


رهام محمد حسن طلبه

Noonan, Maria(2012): Mind maps: Enhancing midwifery' education, Nurse Education Today, University of Limerick, Limerick, Ireland

\title{
THE USE OF DIGITAL MIND MAPS FOR THE DEVELOPMENT OF LIFE SKILLS AMONG PEOPLE WITH ENVIRONMENTAL TEACHERS OF SPECIAL NEEDS AND THE IMPACT ON STUDENTS WITH DISABILITIES ACOUSTICALLY
}

Tolba, Reham, H. M.

Teacher in The Middle valley college, Ministry of Higher Education and Scientific Research

\begin{abstract}
The goal of the present research is to identify the use of mind maps digital for the development of life and environmental skills of those with teachers of special needs and the impact on students with disabilities acoustically and in the light of what has been observed by conducting several interviews with teachers of Special Needs showing a lack of skills of Environmental and Life suit the nature of the sample. To achieve the aim of the research was to follow the quasi-experimental method, and present research relied on existing experimental design on the experimental and control groups were research sample amounted to 60 teachers and 30 students from the Special Needs consisted tools in environmental skills scale for teachers with special needs (electronic), and note card Albaiay behavior Talib.oosafart results for a significant improvement in the life and environmental skills of the experimental sample after the post test, compared to the control group, the research found that there are significant differences between the mean scores of

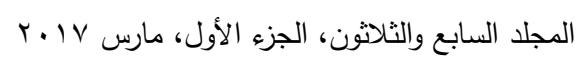


members of the control and experimental groups in the posttest application to measure environmental skills Life among teachers with special needs and for the benefit of the dimensional application, and this is consistent with what researchers in the first hypothesis predicted, confirming the growth occurring in this aspect as a result of the use of mind maps, and that there is a statistically significant between the average scores of students in the two applications pre and post card NOTE positive behavior differences about the environment for the benefit of the dimensional application, and there is a positive correlation statistically significant between the environmental and life skills development for teachers and the high level of positive behavior towards the environment I have a relationship with the students.

Key Words: Digital mind maps - Students with disabilities acoustically 